\title{
Continuing Education Dispositions of NCAA-DI Football Strength and Conditioning Coaches: A Qualitative Analysis
}

Joshua G. Nelson

Follow this and additional works at: https://researchrepository.wvu.edu/etd

\section{Recommended Citation}

Nelson, Joshua G., "Continuing Education Dispositions of NCAA-DI Football Strength and Conditioning Coaches: A Qualitative Analysis" (2017). Graduate Theses, Dissertations, and Problem Reports. 6305. https://researchrepository.wvu.edu/etd/6305

This Dissertation is protected by copyright and/or related rights. It has been brought to you by the The Research Repository @ WVU with permission from the rights-holder(s). You are free to use this Dissertation in any way that is permitted by the copyright and related rights legislation that applies to your use. For other uses you must obtain permission from the rights-holder(s) directly, unless additional rights are indicated by a Creative Commons license in the record and/ or on the work itself. This Dissertation has been accepted for inclusion in WVU Graduate Theses, Dissertations, and Problem Reports collection by an authorized administrator of The Research Repository @ WVU. For more information, please contact researchrepository@mail.wvu.edu. 


\title{
Continuing Education Dispositions of NCAA-DI Football Strength and Conditioning Coaches: \\ A Qualitative Analysis
}

\author{
Joshua G. Nelson \\ Dissertation submitted \\ to the College of Physical Activity \\ and Sport Sciences at West Virginia University \\ in partial fulfillment of the requirements for the degree of \\ Doctor of Education in \\ Coaching and Teaching Studies
}

\author{
Kristen Dieffenbach, Ph.D., Co-Chair \\ Robert Wiegand, Ed.D., Co-Chair \\ Valerie Wayda, Ed.D. \\ Emily Jones, Ph.D. \\ Richard Walls, Ph.D.
}

Department of Coaching and Teaching Studies

Morgantown, West Virginia

2017

Keywords: continuing education, expertise, athletic coaching, strength and conditioning Copyright 2017 Joshua G. Nelson 


\section{ABSTRACT \\ Continuing Education Dispositions of NCAA-DI Football Strength and Conditioning Coaches: A Qualitative Analysis}

\section{Joshua G. Nelson}

Background/Purpose: To explore the continuing education dispositions of collegiate football strength and conditioning coaches in the NCAA-DI. Methods: Qualitative content analysis was used on data collected via online questionnaire and semi-structured interviews to explore the learning habits and values toward career long learning of eight $(n=8)$ active collegiate football strength and conditioning coaches certified with either the National Strength and Conditioning Association or College Strength and Conditioning Coaches Association, and in full time employment as a college strength and conditioning coach for at least ten years. Results: Results identified themes associated with how coaches engage in continuing education throughout their careers and how they value such experiences. Coaches also provided insight in regard to how they felt continuing education could be improved for their personal practice and for future generations of strength and conditioning coaches. Conclusion: Findings support previous literature pertaining to how continuing education can exist as formal, informal, or nonformal and can be meticulously planned or interwoven into the day to day experiences of professionals.

Keywords: continuing education, expertise, athletic coaching, strength and conditioning 


\section{Acknowledgements}

Since I can remember, I have lived, breathed, and studied the "coach's lifestyle." Understood only by those that have experienced the long hours, the rollercoaster ride of success and failure, hirings and firings, transition, family moves, limited financial stability, and the endless pursuit of perfection: coaching exists as the greatest profession in the world. For the past coaches that have contributed so much for future generations of coaches, I hope this can serve as a small addition to the current body of knowledge.

I would first like to thank my loving wife and best friend Rachel Preston Nelson for the love and endless support that she has given me over the past several years. Not only did she support me in every way imaginable, she pushed me to jump when I didn't know where I was going and moved across the country leaving behind family and friends. For this I am truly indebted to her and promise to always love and care for her. Thank you, Love.

I would also like to thank my family for everything through the years. I thank my lovely Mom, Becky Nelson, my Dad, Greg Nelson, and my sister Ashley Nelson for being there for me, for putting up with my mischief, and for always loving me no matter what direction I was running, or what random idea I was chasing. My mom taught me how to work hard, to push, and to have the ability to never quit. She has always been my rock. My dad taught me from an early age how to become a coach and a man. Watching him through the years as a coach taught me how to work with people, how to plan, and how to be great. My sister taught me how to be kind and how to be happy. Her disposition always provided love and support and has always made me want to strive to have warmth in my heart. Thank you Mom, Dad, and Ashley.

In addition to my family, I would also like to thank the many coaches through my career that have been extremely influential on not only my growth as a coach, but also as a man. I had the opportunity to learn from coaches and mentors through the years by both direct and indirect observation of everything they were doing. I watched everything; how they moved, how they planned, how they spoke and taught, and how they worked with people. Thank you.

Three major developmental experiences come to mind as to major influences on where I am today. First, the direct observation of my Dad through the years he was a coach. This was informal observation, but I was able to live the life of a coach before I even knew what I was doing. Second, my time at Emory \& Henry College where I was able to learn from Bob Johnson, Rob Grande, Trey McCall, and Don Montgomery was very influential. Their never ending energy and passion for college athletics and for the development of young studentathletes drives my attitude toward coaching today. Finally, at Baylor University I learned how to never stop and to hustle every second. The lessons I had the opportunity to learn from Coach Kaz Kazadi, Coach Ruf, Coach Althoff and the entire staff were not only influential on my development at the time, but completely changed the way I view coaching, teaching, the business of sports, and more importantly life. Thank you all. 
The time that I spent in Morgantown, WV also changed the way that I view coaching, hard work, and learning. I would first like to thank Dr. Kristen Dieffenbach for her never ending support and guidance as my project chair and advisor in learning how to study and teach the great field of coaching education. Thank you for pushing me to dig deeper into the inner workings of coach education, how to be involved in a lot of different things, and for being my friend. Thank you also to my dissertation committee members Dr. Robert Wiegand, Dr. Valerie Wayda, Dr. Emily Jones, and Dr. Richard Walls who assisted me in this endeavor to becoming a coaching educator. Finally, thank you to Marcus Kinney, Nick Grimes, and Kiel Illg who were such great friends for so long.

Reflecting on this journey brings back an array of memories, emotions, and thoughts. From washing clothes and painting fields at the NCAA Division-III level to playing in the Cotton Bowl at Cowboy's Stadium, the different experiences I have had so far only make me want more. As I move forward, I want to use what I have learned thus far as the foundation for future learning experiences and to positively impact the next generations of coaches the way I was impacted before. The following page includes a list of other influences I would like to acknowledge: 


\section{Emory \& Henry College}

Coach Fred Selfe

Coach Bob Johnson

Coach Rob Grande

Coach Don Montgomery

Coach Trey McCall

Coach TC Calhoun

Coach Tom Manning

Coach Bryan Moore

Coach Joel Gordon

Coach Anthony Frate

Coach Stan Watson

Coach Rob Colley

Dr. J.P. Barfield

Dr. Doug Arnold

Dr. Ron Diss

Dr. Rebecca Buchanan

Dr. Eric Grossman

Coach Josh Wellenhoffer

Coach Marshall Doss

Coach Myra Sims

Coach Dave Griffore

Coach Linda Schirmeister-Gess

Coach Mike Simmons

Coach Gary Kerns

Coach Phil DeCapito

Coach General Franks

Coach Chip Schaffner

Dana Boyd

Sherry Johnson

Beth Funkhouser

D.C. Cobler

Melissa Davis

Dave Brinegar

Monica Hoel

Coach Josh Bullock

Coach Matt Kardulis

Coach Codie Mitchel

Coach Josh Sickles

Coach Matt Duffy

Ann Thomas

Peggy McGhee

\section{West Virginia University Baylor University}

Dr. Kristen Dieffenbach

Dr. Robert Wiegand

Dr. Valerie Wayda

Dr. Emily Jones

Dr. Richard Walls

Dr. Sean Bulger

Carol Straight

Robin McKinney

Coach Marcus Kinney

Coach Nick Grimes

Dr. Kiel Illg

Dr. Wes Meeteer

Coach Jerry Handley

Coach Beth Byron

Coach Nadine Dubina

Coach Dave Retton

Dr. Ryan Flett

Dr. Carl Bahneman

Coach Art Briles

Coach Kaz Kazadi

Coach Chris Ruf

Coach Keith Caton

Coach Justin Hill

Coach Jacob Miller

Coach Chad Cain

Coach Cade Carnett

Coach Tony Shipp

Coach John Griffin

Coach Kale Igboh

Coach Kyle Bolton
Coach Andrew Althoff

Coach Anne Tamporello

Coach Candice Walls

Coach Jana Heitmeyer

Coach Kayln Sticher

Coach Kendall Briles

Coach Jeff Lebby

Coach Tate Wallis

Coach Brett Bufton

Coach Phil Bennett

Coach Chris Achuff

Coach Jim Gush

Coach Randy Clements

Coach Carlton Buckels

Coach Casey Horny

Coach Colin Shillinglaw

Coach Diane McPheeters

Coach Phil Montgomery

Coach Beau Trahan

Coach Matt Knoll

Coach Alison Ojeda

Coach Steve Rodriguez

Coach Teddy Katz

Coach Ian McCaw

Coach Todd Patulski

Coach Jim Grobe

Coach Tracie Hartman

Coach Ellen White

Coach Michael Armille

Coach Taylor Davis

Coach Kevin Donovan
Other Influences

Coach Greg Nelson

Rebecca "Momino" Nelson

Ashley Nelson Childress

Coach Al Childress

Byrd Preston

Suzanne Preston

Fred \& Betty Surratt

Coach Bill Worrell

Coach Bill Strong

Coach David Meredith

Coach Mike Worrell

Coach Charles Campbell

Coach Ethan Reeve

Coach Mike Gentry

Coach Rick Court

Coach Kevin Yoxall

Coach Boyd Epley

Coach Scott Bennett

Coach Mike McGettigan

Coach Donnie Maib

Coach Mark Watts

Dr. Joe Dervay

Capt. Chris Cassidy

Coach Gunter Brewer

Coach Mike Compton

Coach Jim Miller

Dr. Brian Gearity

Coach Billy Wells

Coach Joe Tompkins

Coach Kevin Dehaven

Coach Ryan Brittle 


\section{Table of Contents}

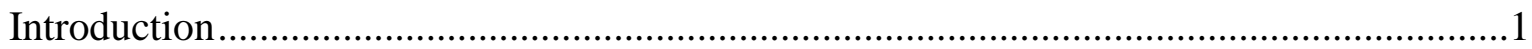

Rationale for Study and Use of Qualitative Methods.....................................................

Problem Statement and Research Questions ...............................................................

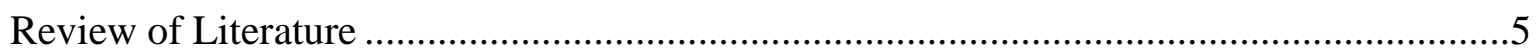

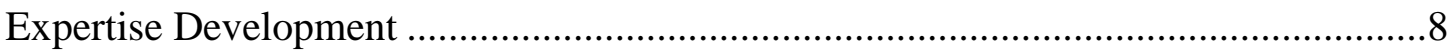

Phases of Expertise Development........................................................................10

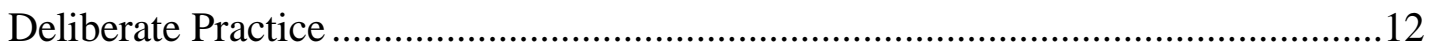

The Development of Coaching Expertise …………………………..........................14

Practices and Habits of Expert Coaches ..................................................................15

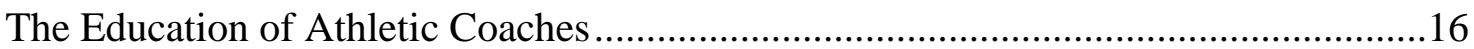

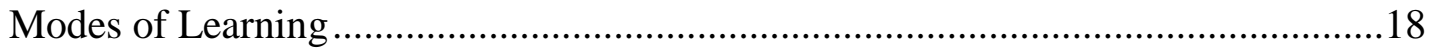

Formal Coach Education.....................................................................................19

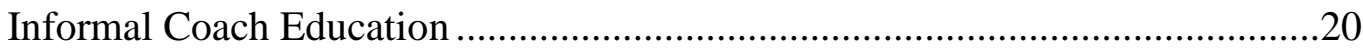

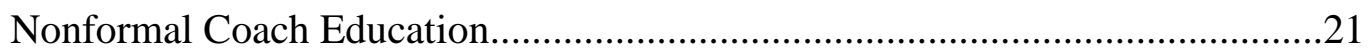

Instructor Involvement in Coach Education ........................................................21

A Journey to Coaching Expertise via Continuing Education.........................................24

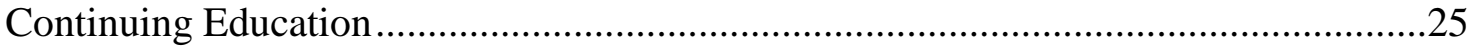

History of Continuing Education ............................................................................26

Conceptualizing Continuing Education ................................................................28

Reid's Quadrant Theory ....................................................................................29

Structural and Core Features of Continuing Education .........................................31

Collegiate Strength and Conditioning Coaching ………..............................................34

Career Evolution of College Strength and Conditioning Coaches ..............................37

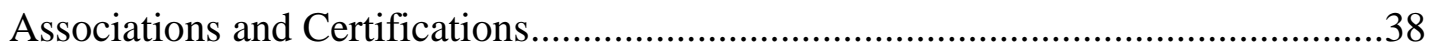

Professional Learning Requirements and Opportunities ...........................................40 
Continuing Education in NCAA-DI Football Strength and Conditioning.....

Method

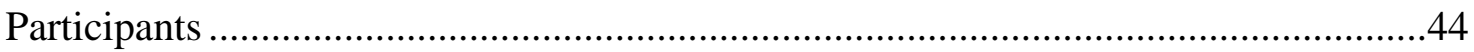

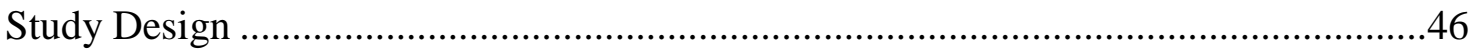

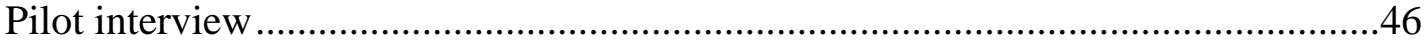

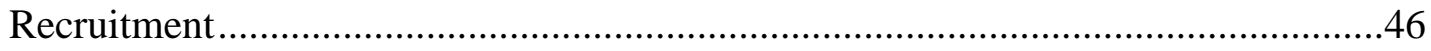

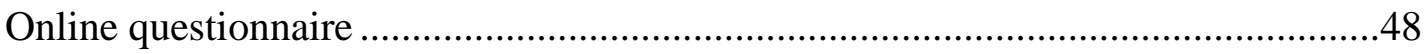

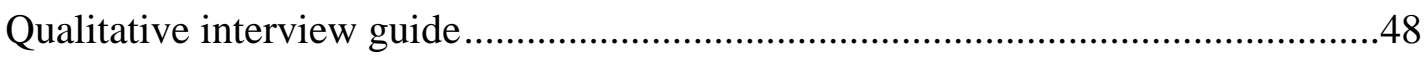

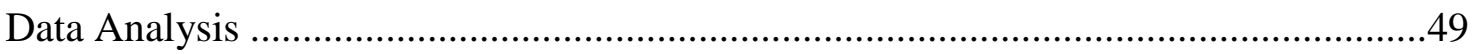

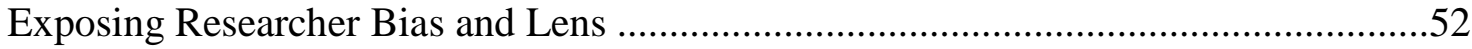

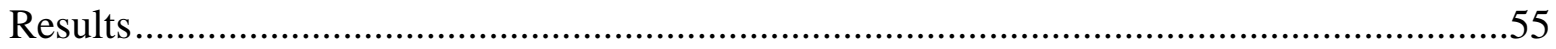

Continuing Education Practices of NCAA-DI Football

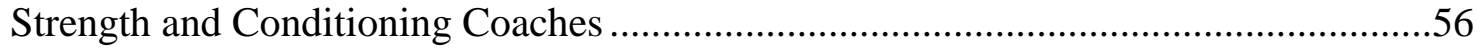

Personal continuing education practices and engagement in learning......................56

Learning through social connections ........................................................56

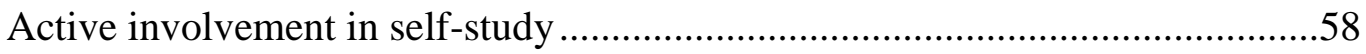

Experience as a vehicle of learning ..........................................................60

Deliberate learning at conference .............................................................6

Enrollment in formal graduate education ..................................................62

Values Toward Continuing Education of NCAA-DI Football Strength and Conditioning Coaches

Values toward coach learning and active leadership behavior with continuing education. .63

Responsibilities and skills of coaches for continuing education learning ...........63

Create nonformal continuing education situations for staff.............................66

Active engagement in professional organizations .........................................68

Attitudes toward professional organizations...............................................68

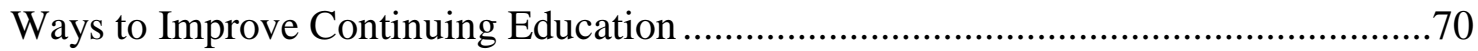




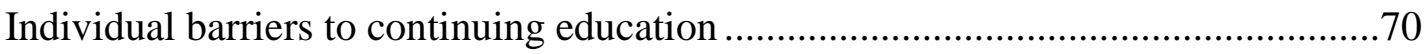

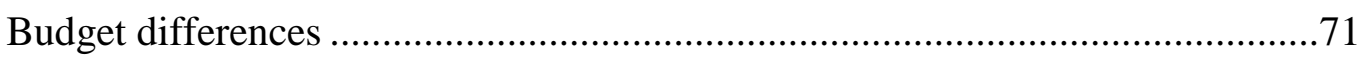

Unity within the field: Bring professionals together.............................................71

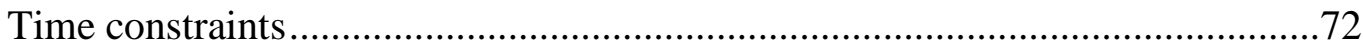

Organizational barriers to continuing education..........................................................72

Suggestions for individual continuing education enhancement.................................73

Be more professional in learning and in practice.................................................73

Differentiate learning experiences .....................................................................

Identify and learn important skills and knowledge.............................................76

Suggestions for organizational continuing education enhancement ..........................76

Lack of singular organization or standardized education .....................................76

NCAA rules inhibit learning of future coaches ………………………………....77

Impact of Personal Background on continuing education Pursuits................................78

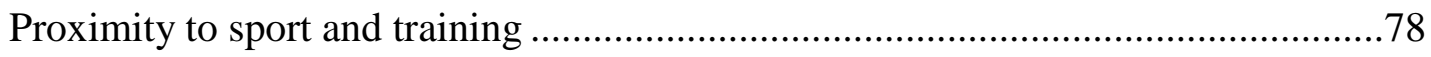

Academic background and proximity to education ................................................... 81

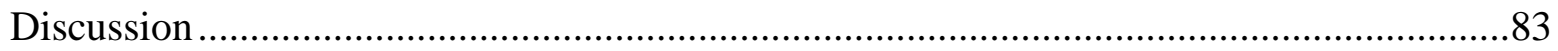

What Continuing Education Experiences do Head College Football Strength and Conditioning Coaches Use Throughout Their Careers?..................................................85

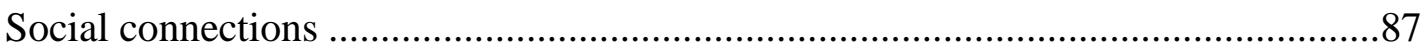

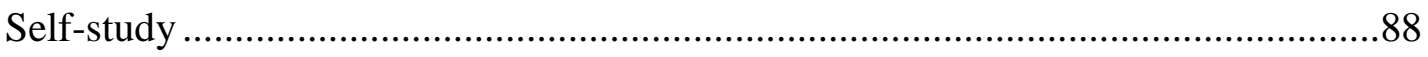

Experience as continuing education learning ..........................................................8

Conference continuing education learning .............................................................90

Graduate school experience ......................................................................................91

What Values do Head College Football Strength and Conditioning Coaches

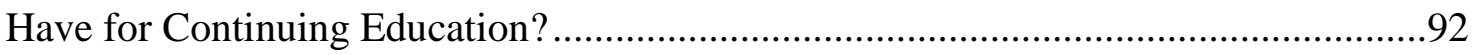

How Can Continuing Education be Improved to Assist Individual Strength and Conditioning Coaches and the Entire Profession? ........................................................95

The impact of NCAA legislation on strength and conditioning coaching .................97 
Individual Backgrounds and Its Impact on Continuing Education ............................98

Limitations of Research......................................................................................... 100

Conclusion and Future Research ................................................................... 102

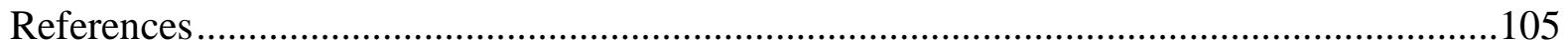

Table 1: Criteria for Web-Based Search for Participants ................................................119

Table 2: Participant Involvement and Values in Continuing Education.............................120

Appendix A: Invitation to Participate Letter and Informed Consent................................121

Appendix B: Pre-Interview Online Questionnaire .......................................................122

Appendix C: Semi-Structured Interview Guide and Script .........................................126 


\section{Continuing Education Dispositions of NCAA-DI Football Strength and Conditioning Coaches: A Qualitative Analysis}

Strength and conditioning coaches are a specialized form of athletic coach and exist as a relatively new player in the world of athletic coaching. Similar to teachers in the education setting (Jones, 2006), such professionals provide instruction and feedback to athletes in regard to different elements of sport performance (Kontor, 1989) and are responsible for a myriad of duties once in the field (Kraemer, 1990; Martinez, 2004; Massey, Vincent, \& Maneval, 2004). Scholarship in exercise prescription and training science (Bompa \& Haff, 2009; Issurin, 2008; 2010) led to the development of strength and conditioning in college athletics (Layden, 1998; McClellan \& Stone, 1986) and the development of professional associations within performance training (Kontor, 1989; The National Strength and Conditioning Association Timeline, n.d.). Since its emergence in college athletics in the 1960s, innovations in training science (Bompa \& Haff, 2009; Issurin, 2008; 2010) require strength and conditioning coaches to remain lifelong learners to continuously improve their practice (Fekete, 1999).

It has been shown that collegiate strength and conditioning coaches come from a variety of pre-professional backgrounds prior to employment (Brooks, Ziatz, Johnson, \& Hollander, 2000; Martinez, 2004; Pullo, 1992) and have different ways of developing as a coach. These include formal coach education (Abraham \& Collins, 1998; Cushion, Armour, \& Jones, 2003; Trudel \& Gilbert, 2006), informal coach education (Cushion et al., 2003; Rynne, Mallett, \& Tinning, 2010), and non-formal coach education (Cushion et al., 2003; Merriam, Caffarella, \& Baumgartner, 2007). Further, such developmental opportunities for coaches exist with varying amounts of instructor involvement that range from very hands on to mostly learner initiated (Werthner \& Trudel, 2006). 
Through continued involvement in a sport and coaching, an athletic coach moves from novice to competent status and progresses toward the development of expertise in their sporting area (Abernathy, 2008; Anderson, 1982; Ericsson, 2003; Fitts \& Posner, 1967). Such progression is noted to take approximately 10 years or 10,000 hours of deliberate practice (Ericsson, 2003). The learning opportunities and coaching experiences the coach is involved in throughout their career can have an impact on their coaching content knowledge and skills and can assist them in their journey toward the development of coaching expertise.

Learning throughout the career of a professional has been referred to as continuing education (Cervero, 2000), ongoing learning (Fekete, 1999), continuing professional development (Armour, Makopoulou, \& Chambers, 2009; Austin, Marinia, Glover, \& Croteaue, 2005; Peck, McCall, McLaren, \& Rotem, 2000), and simply as continuing education (Garet, Porter, Desimone, Birman, \& Yoon, 2001; Guskey, 2002). This study operationally defined continuing education (CE) as the deliberate, career-long learning of a professional with the intention to improve habits, skills, or practice.

Since its emergence among medical physicians in the 1960s (Cervero, 2000), CE has expanded to fields such as pedagogy (Borko, 2004), preventative medicine (Klein, Allan, Manca, Sargeant, \& Barnett, 2009), business (Cervero, 2000), and athletic coaching (Fekete, 1999). Its presence in athletic coaching allows for coaches to be deliberately engaged in improving their coaching content knowledge and consistently progressing toward coaching expertise in their sport. Further, as strength and conditioning coaches hold a wide range of job responsibilities (Brooks et al., 2000; Kontor, 1989; Massey et al., 2004), such longitudinal learning can allow for the development of competencies that can have an influence on their athletes. 


\section{Rationale for Study and Use of Qualitative Methods}

Collegiate strength and conditioning coaches come from a variety of pre-professional backgrounds (Brooks et al., 2000; Martinez, 2004; Pullo, 1992), and that there is no "specific prescription" to follow for becoming an expert coach (Lyoka \& Xoxo, 2011). Because of the unstandardized nature of the field, CE can exist as an influential player in the continued development of individual coaches and in the progression of the entire field (Fekete, 1999). In order to explore the field, the strength and conditioning coach will be viewed as a specialized form of athletic coach, the athletic coach as an educator, and CE as a vehicle for the development of expertise in the field of collegiate football strength and conditioning. Literature exists pertaining to how athletic coaches develop along a continuum of expertise (e.g., Ericsson, 2003; Grant, Dorgo, \& Griffin 2014; Schempp, McCullick, \& Mason, 2006), however there is limited work regarding the learning practices of college strength and conditioning coaches, especially those directly in charge of football training. Further, there is currently limited work about how $\mathrm{CE}$ contributes to the progression or development of expertise of collegiate football strength and conditioning coaches. To examine the ways in which NCAA-DI football strength and conditioning coaches develop expertise through their careers, this study used a composite theoretical framework derived from literature on expertise development, coaching education, and CE.

To address the paucity of scholarly work, qualitative interview methods were used to allow an intimate look into the attitudes toward and deliberate involvement in CE among football strength and conditioning coaches at the NCAA-DI level. Results provide insight for how CE opportunities can be improved for such coaches. A better understanding of the current structure of CE can potentially lead to improvements and more progressive learning opportunities for 
future collegiate football strength and conditioning coaches. Further, as strength and conditioning coaches improve in practice, their athletes may have the opportunity to engage in more progressively designed training sessions, thus directly influencing their performance.

\section{Problem Statement and Research Questions}

College football strength and conditioning coaches exist with the goal of improving the performance related competencies of their athletes (Kontor, 1989). It has been shown that such strength and conditioning coaches come from a variety of pre-professional backgrounds (Brooks et al., 2000; Martinez, 2004; Pullo, 1992), yet little is known about how they work to continually develop throughout their careers and how they feel about such CE. Further, as there is minimal research related to how collegiate football strength and conditioning coaches engage in and perceive CE opportunities, little is known about the perceived impact of career-long learning. In order to better understand how CE is used and perceived by these coaches, the researcher used qualitative interview methods and content analysis to explore the learning dispositions of eight $(n=8)$ NCAA-DI head football strength and conditioning coaches in the NCAA-DI level.

Research questions included:

1. What CE experiences do collegiate football strength and conditioning coaches engage in throughout their careers and why?

2. What forms of $\mathrm{CE}$ are valued by collegiate football strength and conditioning coaches for career development and why?

3. Based on personal experiences of NCAA-DI football strength and conditioning coaches, how can CE be improved? 


\section{Review of Literature}

Athletic coaches are responsible for the development of youth, adolescent, and elite level athletes. Similar to teachers, athletic coaches are active in providing instruction, evaluation, and feedback to their athletes. Past scholarship in sport pedagogy has made associations between how teachers educate students and how coaches train athletes. Jones (2006) has established connections between athletic coaching and pedagogy and provides evidence from other disciplines showing how the use of educational principles by coaches can lead to performance improvements amongst athletes at different levels.

In the area of sport and athletic coaching, strength and conditioning coaches are a relatively new player not emerging widespread until the mid-1980s (Layden, 1998). Similar to other athletic coaches, strength and conditioning coaches actively work as educators with the ultimate goal of improving athletic competencies. Explicitly, strength and conditioning coaches aim to improve performance-related abilities of athletes in regard to muscular strength, power, speed, agility, balance, proprioceptive ability, and sport-specific conditioning (Kontor, 1989;

Massey et al., 2004). Further, the strength and conditioning coach plays an active role in injury prevention in conjunction with the sports medicine staff to return athletes to play following an injury (Kontor, 1989; Massey et al., 2004).

In addition to traditional performance enhancement and injury prevention modalities, the strength and conditioning coach may have other responsibilities including managing pre-game warm-ups, in-game sideline organization, disciplinary actions, and developing and managing budgets for the athletic performance department (Brooks et al., 2000; Massey et al., 2004). With such varying pre-career backgrounds and responsibilities within the job, the strength and 
conditioning coach must always be learning so as not to lose sight of current knowledge and practices most closely affiliated with primary roles of performance enhancement. As strength and conditioning coaches are actively involved in career-long learning, their improved practice can also have a positive effect on athlete development.

The process of career-long learning has been noted as vital for continual progression and integrity of a profession (Cervero, 2000) and since its emergence in the 1960s, has existed with several descriptions. These names include continuing professional development (Armour \& Yelling, 2004; Austin, Marini, Glover, \& Croteau, 2005; Craft, 1996; Cushion et al., 2003), continuing education (Armstrong \& Weidner, 2010; Fekete, 1999; Manners \& Scifers, 2005; Pitney, 1998), learning over time (Carr, Ploeger, \& Drummond, 2007), continuing medical education (Klein et al., 2009) and also as professional development (Gardiner \& Mensch, 2004; Torff, Sessions, \& Byrnes, 2005; Varga-Atkins, Qualter, \& O’Brien, 2009). In this study, all deliberate, career-long learning with the intention to improve habits, skills, or practice will be considered continuing education (CE), and will include all previously mentioned forms of professional learning referenced above.

As career-long CE in different fields has seen rapid growth in the past (e.g. Borko, 2004; Cervero, 2000; Fekete, 1999; Klein et al., 2009), its involvement in the development of strength and conditioning coaches strengthens individual coaching abilities, and aids in the progression of the entire field. To conceptualize the CE experiences of collegiate strength and conditioning coaches throughout their careers, such learning opportunities will be examined using Reid's quadrant approach for organizing CE (Fraser, Kennedy, Reid, \& McKinney, 2007; McKinney et al., 2005), as well as the work by Garet and colleagues (2001) that exposes core and structural features of successful CE. Each theory will help provide insight into how CE is organized 
around the learning needs of professionals as well as how it can provide a comprehensive and longitudinal stimulus for progression.

In a review completed by the primary investigator of Bowl Championship Series division NCAA-DI athletic websites, many different program structures exist within collegiate strength and conditioning. In several instances, programs have the financial resources to have fully staffed and independently operated strength and conditioning programs for football, basketball, and Olympic sports. At other universities, there is a single strength and conditioning program with a staff that services the entire men's and women's athletic program. Despite the inconsistent structure of strength and conditioning programs across the country at the NCAA-DI level, all athletic departments with a football program have at least one individual allocated to develop and direct the football strength and conditioning program. Due to the frequency and consistency of strength and conditioning staffs amongst football programs, this research will be focused on evaluating the CE dispositions of NCAA-DI football strength and conditioning coaches identified in the web-based search (See Table 1).

Strength and conditioning coaches are a form of athletic coach, and coaches have been noted to develop and operate similar to teachers (Jones, 2006). A synopsis of how CE contributes to the development of teachers and coaches will be analyzed to further establish connections between the fields and to show how continued practice in an area can improve professional practice. Finally, a brief history of strength and conditioning will provide a picture of the emergence and development of the field and will set the foundation for an analysis of CE experiences of college football strength and conditioning coaches. The experiences that college football strength and conditioning coaches engage in throughout their career ultimately shape their longitudinal path toward the development of sport expertise in sport performance training. 
Continual learning throughout a coach's career not only can impact their personal development, but can also strengthen the profession and impact the developmental opportunities of many different athletes that they coach. To better explore the learning characteristics and habits of the elite strength and conditioning coaches, literature will be evaluated that explores key areas of expertise development including the three different phases of expertise development, the impact and need for deliberate practice versus experience alone, and finally the habits that expert coaches often possess.

\section{Expertise Development}

The development of expertise exists as a longitudinal experience that requires a great amount of time spent deliberately engaged in an activity. Expert performance is noted by Ericsson (1993, p. 363) as "the end result of individuals prolonged efforts to improve performance." Original work in expertise development leaned heavily on experience alone as the major impetus for growth; however contemporary scholarship has noted that intentional involvement with goals set for improvement are important (Ericsson, 1993).

Early efforts of the exploration of expertise looked primarily at the characteristics that experts exhibited through their experiences. At the time, experts were often identified as those with an "accumulated knowledge, extensive professional experience, and peer nominations" (Ericsson, 2008a, p. 989). This has since been criticized as many professionals identified as "experts" exhibited the inability to outperform their so called "non-expert" peers (Ericsson, 2008a). This was identified in the examination of medical physicians (Elstein, Shulman, \& Sprafka, 1978; Ericsson, 2007) and professionals in psychotherapy (Dawes, 1994). 
Contemporary scholarship shifted from evaluating characteristics of experts throughout their experiences toward the analysis of the process of gaining expertise and the ability to have "reproducibly superior performance in a given domain" (Ericsson, 2008b, p. 989). This marked an important addition to the study of expertise as individuals identified as experts are often in positions where they must outperform their non-expert peers. This superior performance may be especially important amongst experts that directly impact the lives of people that rely on them (i.e., physicians, teachers, athletic coaches).

The above mentioned work in expertise in different fields spurred interest in evaluating expertise and expertise development in sports. Abernathy (2008) notes that work in expertise in sports began to come to surface in the late 1970s and 1980s. During this time, most scholarship that was done with athletes, coaches, and sport evaluated the differences between experts and non-experts (novices) in regard to talent or skill. Although influential in determining characteristics of experts and differentiating them from their less-experienced peers, more modern research is noted to focus more on the actual process of building expertise. Abernathy demonstrates the importance of such scholarship by stating that "any means that can be found to accelerate the acquisition of expertise and to make skill learning more efficient will be exceptionally valuable to athletes, coaches, officials, and administrators alike” (2008, p.1).

Through many years of extensive and deliberate practice, often through engagement in $\mathrm{CE}$, coaches work toward developing coaching expertise. The development of expertise is often thought to take up to 10 years or 10,000 hours of deliberate involvement in an area or activity (Ericsson, 2003). As athletic coaching education has been noted to be limited in scope (Jones, 2000), career long involvement in CE can help coaches continually advance toward expertise in their area while also working to build standardized, foundational knowledge across the field. 
Further, as the job description for strength and conditioning coaches has been noted to be wide ranging (Brooks et al., 2000; Kontor, 1989; Massey et al., 2004), such time spent in deliberate CE can allow such coaches to continue to develop competencies in regard to different kinesthetic modalities. In a synopsis of the characteristics of expert coaches, Schempp, McCullick, and Mason (2006) note that coaches progress toward expertise by navigating a hierarchy of competence. As they note, "everyone begins as a beginner," coaches learn through experience and time spent engaged in their specific sport (2006, p. 146). As coaches develop coaching expertise, they are noted to possess an extensive knowledge base in regard to their sport, instincts to predict future outcomes during game situations, and skills necessary to meticulously plan their practices and games. Further, expert coaches tend to be more autonomous in their behaviors and have more advanced problem solving skills (Schempp et al., 2006).

\section{Phases of expertise development.}

In the development of expertise, several pieces of work have shown that individuals go through different phases of knowledge acquisition. As noted by Fitts and Posner (1967) and later by Anderson (1982), the developmental process of experts exists in three distinct phases. When first learning a skill, an individual engages in a learning process that is often mediated by a teacher or a coach. Fitts and Posner (1967) note this phase as the cognitive phase, and it is characterized by having individuals internalize and organize the information in a manner that is unique to them. In the second phase, noted by Fitts and Posner as the associative phase, the individual begins to accumulate knowledge about the content or skill and begins to develop more organized abilities. Although not fully at the mastery level, it is proposed that an individual in this stage engages in a large amount of learning in order to reach a more competent status. The final stage of skill acquisition is noted as the autonomous stage. It is during this stage where the 
individual exhibits more advanced qualities and often automatic behavior. Further, in this stage, professionals continue to develop and progresses to develop well organized knowledge and skill repertoire (Fitts \& Posner, 1967).

This model is also noted by Ericsson (2003) in a critique of expertise development in sport. It is noted that individuals existing in the cognitive stage of development make efforts to fully internalize and understand the process of their actions. Next, as individuals progress and have the ability to perform actions with minimal thought, they enter into the associative phase. Some individuals are noted to be able to reach this level in "less than 50 hours for most recreational activities, such as skiing, tennis, and driving a car" (2003, p. 64). As skill continues to improve, individuals enter into the autonomous phase. During this phase, they are noted to have the ability to "generate a virtually automatic performance with a minimal amount of effort" (2003, p. 64).

Ericsson (2003) notes that an important aspect of the process of developing expertise is that individuals that reach the autonomous phase must continually seek to engage in challenging situations in order to continually progress. Similar to tenets of training periodization (Bompa \& Haff, 2009; Issurin, 2008; 2010), the concept of avoiding becoming stagnant in practice is avoided by carefully implemented learning stimuli which result in subsequent progression. Ideally, individuals should actively seek to become more competent and educated in their field through their career. Ericsson notes that "expert performers counteract automaticity by developing increasingly complex mental representations so that they can attain higher levels of control of their performance..." (2003, p. 64). Essentially, it is important for professionals to continually work to challenge their internal knowledge structure though a system of intellectual periodization. 
In order to continually improve, coaches must deliberately be involved in coaching situations that require deliberate participation (Ericsson, 2003). It has been shown that to be effective, such learning experiences should be spread throughout the career of a coach (Armour et al., 2009; Garet et al., 2001). Engagement in career-long CE can provide longitudinal learning, and should include a variety (Lyle, 2002) of formal (e.g. Cushion et al., 2003; Mallett, Trudel, Lyle, \& Rynne, 2009; Trudel \& Gilbert, 2006), informal (e.g. Cushion et al., 2003; Rynne, 2010), and nonformal (e.g. Cushion et al., 2003; Merriam et al., 2007) learning experiences. The continuous involvement in such CE can allow coaches to experience many different learning opportunities that both challenge their abilities and expose them to novel concepts and ideas.

\section{Deliberate practice.}

In an extensive review of literature in areas of chess, dance, and athletics, Ericsson (2008a) notes that the development of expertise is not related to innate traits, but rather to abilities learned through ongoing engagement in an activity. Further, such development requires high quality practice in order to hone skills necessary to be successful in an area. Regardless of the activity, the development of expertise requires a dedicated involvement with the activity at a high level with the ultimate intention of improving performance (Ericsson, 2008a). Career-long involvement in learning experiences can put a professional in position to develop toward such status.

Deliberate practice should be thought of as intentional efforts aimed at improving performance (Ericsson, 1993). More focused than simple experience or involvement in an activity or task, deliberate practice is "highly structured activity," and often used to improve on a 
specific weakness or areas of improvement (p. 368). Further, deliberate practice is typically monitored, is not always fun, and may potentially not have instant feedback related to involvement in the activity (Ericsson, 1993).

Ericsson (1993) notes that during the journey toward expert practice, individuals must navigate several constraints that may discourage or hinder continued development. These constraints may include external limitations such as limited opportunities to practice or internal battles such as a lack of motivation. Gladwell (2008) adds that individuals may also be hindered by factors such as physical ability, support systems, or geographical isolation that may play a contributing role in a person's development.

Ericsson continues by noting that the long-term commitment toward development is what makes expert status difficult to obtain (1993). In order to reach expert status, an individual must develop within the following bounds. First, deliberate practice requires an individual have the opportunity and possibly a support system to promote continued practice. This may include access to an activity or a mentor that provides guidance and backing. Next, individuals must be internally motivated to continue to be engaged in deliberate practice. As long-term involvement in working on improving practice is not always enjoyable, individuals must see the bigger picture and be able to operate without instant gratification. Lastly, engagement in deliberate practice requires a lot of focus and energy for high quality practice and must be spread out over time in order to prevent burnout or exhaustion. This makes involvement in deliberate practice more challenging as individuals must commit to being consistent in their involvement over the long-term (Ericsson, 1993). 


\section{The development of coaching expertise.}

It has been noted in past literature that the journey toward expertise begins at a young age (Ericsson, 1993). This is present in the development of sport expertise and later in coaching expertise. Early in the development of an athlete or prospective coach, individuals are often involved in a variety of activities and practice. Further, many coaches have shown a lifelong involvement in expertise development by their "unremitting and enduring commitment to their sport" (DeMarco \& McCullick, 1997, p. 37). It is during this long-term involvement in sport where they developed not only a personal identity as a player and prospective coach, but also an understanding of the technical and tactical aspects of their sport.

The development of expertise in coaching is unique in that coaches who participated in athletics in their youth had the opportunity to informally observe their coaches and their behaviors. This was first noted in past literature as the apprenticeship of observation period (Lortie, 1975). The apprenticeship of observation period is most often described by the evaluation of teachers in education and their previous experiences as students (Lortie, 1975). As teachers participated in school experiences as a student, they are thought to have indirectly learned how to become a teacher by being in close proximity to educators throughout their lives. Then, once in the field as a vetted teacher, they often revert back to many of the same teachings they indirectly observed from the educators that they once were most close to (Lortie, 1975).

Similar to the development of teachers, coaches may also experience this as well. Throughout the playing career of an athlete, these individuals may have the opportunity to view the actions and results of the behavior of the coaches that they have been around. This makes the early developmental experience of athletes very sensitive to the teachings and habits of youth 
and scholastic coaches. This can be even more important for prospective coaches in their journey up the ladder as an athlete and then a young coach.

\section{Practices and habits of expert coaches.}

The development of expertise requires many years spent intentionally involved in an activity (Ericsson, 1993). Further, this involvement is often coupled with the goal of improving personal performance. Experts have been shown to hold extensive knowledge bases, be automatic in behavior relevant to analysis and instruction, and have the ability to make positive decisions using intuition (De Marco \& McCullick, 1997; Schempp et al., 2006). The ability to draw on past experiences and to make quick decisions is integral in the high stakes environment of competitive sport.

Throughout the developmental process, expert coaches show the tendency to spend a lot of time working to learn as much as possible about their sport and coaching. Further, they tend to develop and maintain a vast knowledge for all areas of their sport (De Marco \& McCullick, 1997; Schempp et al., 2006). These individuals often are very verbose when speaking about coaching, utilize a variety of resources to gain knowledge, and possess an impressive library for later reference. Further, expert coaches often spend a lot of time in planning and reflection of their team's performance as well as their personal practices. This knowledge base allows quick analysis and feedback to be given in different coaching situations (De Marco \& McCullick, 1997; Schempp et al., 2006).

Expert coaches are often times very perceptive in analysis of performance and have the ability to provide concise feedback specific to athlete behavior (De Marco \& McCullick, 1997; Schempp et al., 2006). Coaching skills are typically smooth in nature and seem to be conducted 
with little effort. Further, instruction and feedback are usually fluid and can be adjusted to meet the needs of the athlete or audience. As these skills are automatic in nature, coaching effectiveness is improved thus impacting the learning environments of athletes (De Marco \& McCullick, 1997; Schempp et al., 2006).

Through years of success and failure in their sport, expert coaches develop the ability to make decisions based on intuition (De Marco \& McCullick, 1997; Schempp et al., 2006). This "gut sense" exists from the many different experiences that coaches have experienced throughout their careers and often allows the coach to make quick decisions and possible adjustments to their plans. This intuition, however, does not mean that coaches do not fully evaluate problems and situations that arise. In fact, expert coaches have been shown to actually spend more time analyzing a problem than their less experienced peers prior to devising a solution (De Marco \& McCullick, 1997; Schempp et al., 2006).

To better understand the learning experiences of coaches and their path toward expertise, the following sections will be devoted to the exploration of different opportunities that coaches have for development. First, a look at the different educational opportunities of athletic coaches will be explored as will different theoretical constructs of CE in various fields. This will set the stage for the analysis of collegiate football strength and conditioning coaches and their CE experiences throughout their journey toward expertise.

\section{The Education of Athletic Coaches}

Despite the traditional nature common of much coaching development in the United States, the development of more structured coaching education programs have assisted in the progression of the field. Coach education can take place throughout a coach's career and can 
take many forms ranging from formal classroom experiences (Mallett et al., 2009; Trudel \& Gilbert, 2006), to informal experiences such as workplace learning (Rynne et al., 2010), or internship experiences (Cushion et al., 2003). For many successful coaches, learning is longitudinal and often occurs throughout their career (Cushion et al., 2003), and such experiences can help a coach work toward the development of expertise in their profession.

In a review of the history of coaching education programs, Trudel and Gilbert (2006) explored several different programs that have shaped the structure of the current coach education scene. Since the 1970s, coach education programs have been developed in Australia (Woodman, 1989), Canada (Coaching Association of Canada, 2011), and the United States (American Sport Education Program, 2011). Each of these programs was set up in a very structured fashion and was developed to combat potential legal/ethical issues that could potentially ensue during coaching and working with athletes (Trudel \& Gilbert, 2006). Ultimately, these programs provided the foundation for future development of national and independent coaching education programs.

Building upon the basic foundations set forth by early coaching education programs, current organized coaching education exists in many forms and with both positive and negative aspects. In research about the current structure of coaching education, Jones (2000) notes that coach education in the United States is an insignificant factor in the development of coaches. Further, Jones contests that current coach education is inauthentic and does not translate to the actual practices of coaching and athletics. The separation that exists between education and athletics makes it difficult for coaches to merge what is learned in organized education to practice. Ultimately, it is noted that efforts need to be geared toward providing a better system of giving coaches what they need throughout their careers to build and use content learned in 
coaching education (Jones, 2000). The evaluation of different forms of coach education via career long $\mathrm{CE}$ is the foundation of this study and as more is known about the CE habits and practices of college football strength and conditioning coaches, more positive experiences for subsequent generations of coaches can be cultivated.

\section{Modes of learning.}

Since the development of established coaching education programs (e.g. American Sport Education Program, 2011; Coaching Association of Canada, 2011; Woodman, 1989), research attempts have been aimed at defining and learning about different trends in how and what coaches learn and develop. It has been established there exists many forms of coach learning opportunities that span from organized and structured coaching development systems (Mallett et al., 2009; Trudel \& Gilbert, 2006) to informal and individualized experience based programs (Cushion et al., 2003; Reade, Rodgers, \& Spriggs, 2008).

Athletic coaches also learn in different arenas, with unique delivery methods, and with varying amounts of structured learning and hands-on experiential learning. Further, coach education can exist as formal (eg. Mallett et al., 2009; Trudel \& Gilbert, 2006), informal (eg. Cushion et al., 2003; Lave \& Wenger, 1991; Rynne et al., 2010), or nonformal (eg. Cushion et al., 2003; Merriam et al., 2007), and with varying amounts of instructor involvement (eg. Werthner \& Trudel, 2006). With such variance in learning experiences, the developmental paths of coaches are both individualized and unique as compared to other coaches' journeys (Cushion et al., 2003). There is limited work on coach development (Gilbert, Côté, \& Mallett, 2006), especially in regard to NCAA-DI football strength and conditioning coaches experience with CE. 
A look at the different forms of coach education via $\mathrm{CE}$ can provide insight into how coaches develop their knowledge base and how they progress toward coaching expertise.

\section{Formal coach education.}

Coaches have the ability to learn and develop from many different learning formats. In an analysis of how coaches develop, Mallett et al. (2009) notes that coach development is "an all-encompassing term that refers to the process leading toward enhanced expertise" (p. 325). Organized learning situations, often termed as formal coach education, exist in structured environments where coaches learn material from an established curriculum. Often regimented and constructed with clear competencies, these learning situations provide coaches with valuable "knowledge/competencies to be taught and mastered by coaches" (Mallett et al., 2009, p. 328).

Another form of formal coach education relates to large scale coach education programs (Trudel \& Gilbert, 2006). When involved in a large-scale program, coaches engage in a structured setting that is embedded within a course of study and involvement is based on "the assumption that coaches exist on a continuum from novice (beginner) to expert (master)" (Trudel \& Gilbert, 2006, p. 518). Typically, such programs operate with three components: a) coaching theory, b) sport specific techniques and c) coaching practice. Through engagement in each of the components in large-scale programs, coaches are thought to gain a comprehensive background of all facets of coaching (Trudel \& Gilbert, 2006).

Unfortunately, work in athletic coach education has also shown that organized learning is limited in the range of the content covered in coursework (Abraham \& Collins, 1998). Further, although formal coach education provides organized and structured learning opportunities, there exists much criticism surrounding the effectiveness of such curriculum based environments 
(Cushion et al., 2003; Trudel \& Gilbert, 2006). Scholars recommend the need for further investigation of how coaches ultimately learn and how new information should be delivered to and disseminated among professionals.

\section{Informal coach education.}

Coach education can also take place outside of formalized education and without an externally developed structure. Known as informal learning, such education can take place in other areas of professional practice (Cushion et al., 2003) and within the workplace (Rynne et al., 2010). Specific examples may include learning from day to day experience of being a coach, through self-study or conference attendance, and from interactions with other professionals in the field. During these situations, individuals can learn from the experiences or social interactions they have with their colleagues, or in an authentic setting (Rynne et al., 2010).

Within informal learning experiences, coaches often engage with other coaches that share similar interests, directions, and competencies. Legitimate peripheral participation, coined by Lave and Wenger (1991) and later noted in the theory of Communities of Practice by Wenger (2000), describes the situated learning experiences that occur via informal interactions within a group of practitioners that share common interests and directions. Such communities of practice allow members to learn from like-minded peers and to develop a shared appreciation and ownership toward personal and group development. Present in athletic coaching clinics (Vickers, 2007) and in day to day coaching operations (Culver \& Trudel, 2008), involvement in situated learning and communities of practice allow coaches to progressively learn and develop from their like-minded peers in a longitudinal and career long fashion. 


\section{Nonformal coach education.}

Often times, during the developmental process of a coach, individuals engage in systematic learning that is not affiliated with an educational organization. Although not organized around a solidified curriculum, such nonformal learning settings are guided by a leader competent in the field (Cushion et al., 2003) and exist as learning opportunities that are structured, but not institutionalized (Merriam et al., 2007). Examples of nonformal coach education may include staff development programs or organized internship program. Drawing from work in generic adult learning, Merriam and colleagues note that nonformal learning opportunities are often "short-term, voluntary, and have few prerequisites" (p. 30). This ultimately allows for more individuals to take part without the need for large time commitments.

In an evaluation of nonformal learning, Cushion and colleagues (2003) discuss how mentoring can be extremely valuable for the development of proficient coaches. Later, it is also noted that it is important for "mentors to have established the appropriate position in the sporting and coaching hierarchy" (p.223). This ensures that the mentor is both respected and knowledgeable in his or her sporting area. As a major issue in coaching education is deciphering how knowledge and practice should be disseminated and implemented into a program, the use of mentor coaches can provide a valuable instructional method for such competencies (Cushion et al., 2003).

\section{Instructor involvement in coach education.}

In addition to grouping coach learning in terms of type of program, development can also be categorized based on the degree in which mentors or instructors have influence on a developing coach's learning experience. Throughout a coach's career, as they engage in various 
forms of CE, different degrees of instructor involvement can weigh heavily on their development as a professional. Using Moon's (2004) generic view of learning, Werthner and Trudel (2006) evaluate the coach development process by organizing learning into two categories: a) learning like "building a brick wall", and b) learning as "a network" (p. 199-200). In each of these methods of learning, the coach is subjected to an environment shaped to organize and develop knowledge competencies.

By "building a brick wall," the coach organizes content provided by a regimented program and instructor (p. 199-200). Knowledgeable instructors orchestrate the content, the learning process, and ensure learners are advancing. It is noted by Werthner and Trudel that "it is difficult to separate learning from instruction because, in this without instruction there is no learning" (2006, p. 199). As the learner exists within a structured and guided environment, they shape their understandings based upon the foundations built by their leaders.

When shaping learning following the network design, coaches are in a more informal environment where they have the ability to interact with different professionals in their field (Werthner \& Trudel, 2006). Within the network approach of learning are unmediated and internal learning situations. Unmediated situations place the learner in control of what he or she learns without formal guidance by an instructor. This type of learning is very beneficial for the learner as he or she gets to choose what is most valuable and needed for development. This may also be a negative, as individuals without strong individual learning skills can struggle. Another area of learning within the network paradigm takes place internally or through reflection and internal assessment. During this type of learning, the coach reviews and reflects on their own actions and builds knowledge through experience (Werthner \& Trudel, 2006). 
Although very similar to other categories of learning, characterizing coach learning as creating a wall or as a network allows a better understanding of how professionals ultimately develop. Through organized and mediated learning, professionals have the assistance of a trained individual who has preexisting knowledge. On the other hand, through unmediated and internal learning, the coach is placed with the responsibility of finding and developing his or her own learning opportunities. A major note here is that regardless of the degree of instructor involvement, there exists elements of social learning; either with a capable teacher or knowledgeable peers.

The development of coaches can take many different forms ranging from completely standardized and sterile formal education, to very open and casual learning formats. As previously noted, each learning opportunity can exist with positive and negative outcomes. With so many different options, it is noted by Lyle (2002) that coaches should engage in different types of coach education throughout their career in order to get a more rounded experience. Such differentiated longitudinal learning can potentially improve a coach's effectiveness as a leader and may also have a positive impact on the development of their athletes.

A unique sub-set of athletic coaches, NCAA-DI strength and conditioning coaches come from a wide variety of backgrounds and exist with a wide range of job responsibilities (e.g. Brooks et al., 2000; Kontor, 1989; Massey et al., 2004). In order to continually develop coaching competencies in these different areas, career-long learning or CE can be beneficial in the overall development of the strength and conditioning coach. The different coach education experiences, whether formal (Cushion et al., 2003; Mallett et al., 2009; Trudel \& Gilbert, 2006), informal (Cushion et al., 2003; Rynne et al., 2010), or nonformal (Cushion et al., 2003; Merriam 
et al., 2007), spread longitudinally over the course of coaches' careers can help improve their abilities to impact athlete development. Further, consistent engagement in CE amongst college football strength and conditioning coaches can help strengthen and continually improve coaching skill thus positively impacting the practice and knowledge base of the entire field (Fekete, 1999).

\section{A Journey to Coaching Expertise via CE}

Coaches who engage in a career of CE can improve their overall effectiveness when teaching athletic skills and in providing feedback to athletes. This pushes them toward the development of coaching expertise. Such coaches can combat stagnation of their content knowledge and coaching repertoire by being lifelong learners. Horton and Deakin (2008) note that in comparison to their less experienced peers, expert coaches display more organized knowledge specific to their sport and possess the ability to precisely analyze, diagnose, and provide feedback relative to performance. Such skills, common of an expert coach, are developed through years of experience and "results in feedback and error correction that have immediate and large impact on skill development" (Horton \& Deakin, 2008, p.76).

Strength and conditioning coaches exist as a specialized form of athletic coach with a myriad of duties and responsibilities (Brooks et al., 2000; Kontor, 1989; Massey et al., 2004). Further, as coaches and teachers are similar in practice (Jones, 2006), engagement in CE throughout the career of a strength and conditioning coach has the ability to improve professional effectiveness (Garet et al., 2001) and can have a positive effect on athlete development (Guskey, 2002). As collegiate strength and conditioning coaches are actively engaged in career-long CE, each strength and conditioning coach can see individual improvement and can help the progression of the entire field. 


\section{Continuing Education}

CE can put individuals in position to improve their practice, and exists in many fields including athletic coaching (Fekete, 1999), business (Cervero, 2000), general pedagogy (Borko, 2004), and medical fields (Klein et al., 2009). As noted by Armour and colleagues (2009), in most of these areas, the parent organization, institution, or other affiliation maintains and regulates $\mathrm{CE}$ for its employees in an attempt to stay current with evidence based practice. Further, CE is often offered in short engagements over a short span of time and largely exists as directed lectures and hands-on experiences that are strategically geared toward improving the practice of professionals. Most CE is designed for a specific purpose and tangible goal in hopes that those involved can employ the newly introduced material. Unfortunately, this is often a problem as such brief periods of intervention tend to elicit marginal results. Because of this, many organizations look to use the more extended, sequential opportunities for their employees (Armour, et al., 2009).

Career-long CE has been referred to by terms such as ongoing learning (Fekete, 1999), continuing education (Cervero, 2000), and recently as continuous professional development (Armour et al., 2009; Austin et al., 2005; Peck et al., 2000). In this scholarship, all forms of professional learning following entry into the field will be considered simply as CE. Such learning has been defined by Austin et al. (2005) as “...systematic, ongoing, self-directed learning” (p. 26). Later, CE for medical professionals was described by Peck and colleagues (2000) as "the process by which health professionals keep updated to meet the needs of patients, the health service, and their own continuing education" (p. 432). A much more inclusive and explicit definition, Peck and colleagues offer ideas that show how CE is focused on the well- 
being of the clients involved in the service, the organization as a whole, and the professional growth of individuals.

More closely related to the education of athletic coaches and their involvement in the development of athletes, CE of a teacher also leads to improved knowledge and effectiveness. CE in education was defined by Guskey (2002) as "systematic efforts to bring about change in the classroom practices of teachers, in their attitudes and beliefs, and in the learning outcomes of students" (p. 381). Further, this posits that as teachers engage in CE throughout their careers their teaching effectiveness improves thus enhancing subsequent learning experiences for their students. As coaches operate in similar fashion to educators (Jones, 2006), CE can help improve their ability to work with athletes thus enhancing athlete development.

\section{History of CE.}

In an exhaustive review of literature, Cervero (2000) notes that CE originated in the 1960s with a series of studies directed at the lifelong learning processes of medical physicians. It was shown that in order for doctors to be at their highest potential and to be current with medical advances, they would have to remain lifelong students. A decade later, in the 1970s, more disciplines began to catch on to the idea of a continuing learning environment for their staff and employees. Often used for recertification processes, employers began to require that members retain information and content vital to the organizational structure of the company. The 1980s brought a surge in CE movements in all professional areas; affiliations in engineering, accounting, pedagogy, and medicine led the way and others gratuitously followed. This era marked a period of increased accountability for all involved in the progression of major industries and organizations (Cervero, 2000). 
CE in the 1990s sustained prominent growth and expanded to even more professional areas. Cervero characterizes the ten year span of the 1990s by four distinct trends in development. First, it was proposed that any and all CE in the workplace surmounted any external or corporate CE. It was suggested that because organizational figures can provide individualized instruction to employees that is prescribed uniquely for the progression of a company, individuals can gain and internalize more content. It was also proposed that individuals continually learn through experience and all opportunities for practice allow for development (Cervero, 2000).

Cervero's second and third trends suggest that universities and CE entities play a major role and were extremely advantageous for the CE enterprise. The strong affiliation to consumer organizations these institutions have enhance opportunities for guidance and resources to offer progressive learning experiences. Finally, it was noted the use of CE is an expanding trend, and most organizations are engaged in some form of this educational experience to regulate the practice of employees (Cervero, 2000). Used as a method to ensure quality control in the workplace, the institutionalization of CE can allow organizations to ensure their employees actively work to improve their professional practice and skills.

A relatively new player in the world of CE is athletics and those individuals engaged in coaching. In the past, progressive growth among coaches has been established as requisite behavior for successful and prominent teams (Cushion et al., 2003). Unfortunately, many athletic coaches are resistant to new trends regardless of how rich the evidence may be from the empirically derived findings (Cushion et al., 2003). As they become successful at utilizing and implementing evidence based practice, it is likely that more coaches will take advantage of CE opportunities. 
For many professionals, after the university preparation phase, they enter full bore into the inner workings of their profession without a systematic means of continual learning. First shown in the medical field (Cervero, 2000), engagement in CE was acknowledged to be a characteristic of successful practitioners. Especially evident in health services (Klein et al., 2009), education (Armour et al., 2009), and athletics (Fekete, 1999), research indicates that an ongoing, career-long educational regime can provide professionals with a competitive edge over other professionals who do not employ such progressive learning strategies. This may also prove important in fields that have patients, students, and athletes that rely heavily on a doctor, teacher, or coach for positive outcomes.

Similar to the interactions between teachers and students, coaches and athletes engage in relationships that involve teaching and learning. Developing athletic skills, providing relevant feedback, and supervising athletes are all closely related to daily activities of teachers and thus demonstrate a close relationship between the two professions (Jones, 2006). The relationship presented by Jones provides tangible evidence why career-long learning of athletic coaches is similar to that of teachers, and work by Gilbert and colleagues (2006) extends the argument to show the competencies of coaches are integral in the development of their athletes. As previous work (Guskey, 2002) has shown that CE among teachers works to improve the learning outcomes of students, so too can CE for athletic coaches in regard to athlete development.

\section{Conceptualizing CE.}

Career long CE can help develop individual competencies and progress professional fields (Cervero, 2000; Fekete, 1999). Unfortunately, as noted in the physical education literature by Armour and colleagues (2009), CE is often times very brief, impersonal, and irrelevant to 
improving the practice of teachers. This is an issue, as CE can expose professionals to innovative methods and trends that can potentially improve their practice, and their involvement in such learning is integral for professional growth.

In order to better understand the CE experiences that professionals have through their careers, an analysis of three conceptual frameworks for analyzing CE will be outlined. Next, CE experiences will be further broken down by evaluating the actual activities that professionals experience. The evaluation of Reid's Quadrant Theory (Fraser et al., 2007; McKinney et al., 2005) and Garet and colleagues' (2001) study of structural and core features of CE will help explore how $\mathrm{CE}$ experience influences teacher outcomes. In addition to other existing literature on expertise development (e.g. Cervero, 2000; Ericsson, 1993; Schempp et al., 2006), these conceptual ideas will be the foundation for the evaluation of the different experiences that NCAA-DI football strength and conditioning coaches have in regard to CE.

\section{Reid's Quadrant Theory.}

One framework for the evaluation of $\mathrm{CE}$ includes organizing learning experiences into sectors or "quadrants" (McKinney et al., 2005, p. 160). In Reid's organization of teacher CE, learning experiences are categorized into four sectors dependent upon the degree of spontaneity of the event (planned/incidental) and by the extent that it is formally or informally delivered. Formal experiences were noted to be "those explicitly established by an agent other than the teacher" (McKinney et al., 2005, p. 160) and included things like coursework or classes. On the other hand, informal CE was noted to be activities that were "sought and established by the teacher (McKinney et al., 2005, p. 160) and included networking and self-study. Within these 
experiences, the different sectors can be further broken down into elements such as depth and specificity of content (e.g. specific vs. general, infield vs. out of field learning opportunities).

In addition to evaluating $\mathrm{CE}$ as either formal or informal, Reid's organization also can explore the degree in which a learning activity is either planned or incidental in nature (McKinney et al., 2005). This pertains to how the activity was organized. Planned CE activities may exist as formal or informal but have an element of planning (i.e., agenda, planned meeting place, specific participants). Incidental CE activities are not planned and may occur by chance. These may include a random encounter with a colleague, or meeting and networking with new peers at a conference. Within the organizer, any CE experience can be analyzed dependent to how it is planned and how formally it exists (McKinney et al., 2005).

The use of Reid's Quadrant Theory provides a lens in which to view various CE experiences that different professionals use through their career. Provided the intricacy of CE and the vast backgrounds that many professionals have in their career, a model such as this allows for the comparison of different CE experiences and their impact on career-long learning. Further, organizing CE into such a framework can allow analysis of the effectiveness of such learning experiences and perceived impact of the CE as seen by the professionals.

In addition to exploring how $\mathrm{CE}$ is planned and organized, it is also beneficial to evaluate content covered, duration, and setup of the activity, and the degree in which such learning experience stirs future ongoing learning. In education, it has been shown that the implementation of a solidified CE program can greatly influence the practice of teachers. Garet et al. (2001) echo this as they note that "the success of ambitious education reform initiatives hinges, in large part, on the qualifications and effectiveness of teachers" (p. 916). Thus, as 
teacher efficacy improves, student learning should follow. Further, as student learning is the main goal of most education systems, improving teacher practice should be recognized as an integral part of the student development program (Garet et al., 2001). Much like the education field, as athletic coaches develop and operate similar to teachers (Jones, 2000) the continuous development of athletic coaching competencies can be influential on athlete development (Gilbert et al., 2006).

\section{Structural and core features of $C E$.}

CE is continued to be conceptualized by Garet and colleagues (2001) as they identify two elements that categorize different forms of professional learning; structural features and core features. Structural features are noted to be the actual organization and composition of the CE activity, and include, "the form of activity, the duration of the activity, and the degree to which the activity emphasizes the collective participation of groups of teachers from the same school" (pp. 919-920). Core features, or the actual material that is delivered in the CE involve, "the degree the activity has content focus, the extent to which the activity offers opportunities for active learning, and the degree to which the activity promotes coherence in teachers' continuing education" (p. 920). Both structural and core features of the CE are defining characteristics which shape the overall goals of the professional learning experience.

The form of CE activity, a structural feature, can be divided into two types of learning experiences: traditional and reform (Birman, Desimone, Porter, \& Garet, 2000; Garet et al., 2001). Traditional CE is the most common form of professional learning and is characterized as existing outside of the workplace and is often organized with lecture style delivery from a moderator or expert in the given field. Examples of such traditional CE include "workshops, 
institutes, courses, and conferences" (Garet et al., 2001, p. 920). Unfortunately, due to its lack of depth, short term existence, and mass market delivery, such forms of CE are noted to be ineffective in helping enhance teacher learning (Armour \& Yelling, 2004; Birman et al., 2000; Garet, et al., 2001)

In response to the criticism directed toward traditional forms of $\mathrm{CE}$, Garet and colleagues (2001) propose that reform style CE can offer teachers a better form of professional learning. Reform style CE is seen in such activities such as "study groups or mentoring and coaching" (p. 920). Typically, reform style CE takes place during day to day practice and during actual teaching practices. It is noted that as such reform style CE is integrated into the actual workday, professionals may be more inclined to participate over an extended time (Birman et al., 2000; Garet et al., 2001).

Possibly more important than the actual type of CE offered is the duration of the actual professional learning experience (Garet et al., 2001). It is noted in other literature that CE that is longitudinal or extended over a period of time is more effective than singular bouts of learning in helping teachers learn new skills (Heibert, et al., 1999). Garet and colleagues (2001) note that the duration of $\mathrm{CE}$ is influential on professional learning for two reasons. First, longitudinal CE is, "more likely to provide an opportunity for in-depth discussion of content, student conceptions and misconceptions, and pedagogical strategies" (pp. 921-922). This allows individuals engaged in professional learning experiences to better internalize content and to link pre-existing ideas to newly learned concepts. Secondly, continuous CE activities "allow teachers to try out new practices in the classroom and obtain feedback on their learning" (p. 922). This ultimately allows the teacher to see how the strategies learned from the CE can actually be applied to different situations in practice. 
Garet and colleagues (2001) discuss that an important factor in the effectiveness of CE is the extent to which it is organized around the collective participation of all participants involved. As professionals are involved in an organized improvement program, they have the ability to work together and to develop as a group. Similar to social learning theories (Lave \& Wenger, 1991; Wenger, 2000), such opportunities allow professionals to learn and develop from interactions with their peers. Ultimately creating a "shared professional culture," collective participation can benefit all teachers involved in the process (Garet et al., 2001).

It has been shown that there is limited scholarship on what teachers actually learn within CE (Garet et al., 2001). The content that is covered in activities, a "core feature" of CE (Garet et al., 2001), is often brief and limited in scope (Armour et al., 2009) yet is noted to be extremely important to teachers in their learning experience (Birman et al., 2000). Some CE focuses largely on how teachers should plan and implement classroom concepts, while other CE leans more toward the development of an enhanced content knowledge in a particular content area (Garet et al., 2001). While each of the different forms of CE helps improve teaching in a unique manner, Hiebert and colleagues (1999) note that there should be efforts geared toward developing both teaching skills and abilities to understand how children learn.

An integral ingredient in the improvement of education, $\mathrm{CE}$ is beneficial for both teachers and student learning (Armour et al., 2009). Garet and colleagues (2001) further discuss that active learning is integral in CE for teachers, as it allows teachers to actively engage in real-life teaching situations while being critiqued by a mentor or peer. This allows professionals to selfassess their practices, and is noted as being linked to a larger teacher improvement program that parallels set standards and goals for those involved. As activities are linked together, teachers can feel confident that their CE efforts positively impact their teaching abilities and professional 
skills (Garet et al., 2001) and that they are working toward improving student learning (Armour et al., 2009).

Just as CE that is organized around the collective participation of teachers can be influential toward the development of professional practice, so too can CE that is constructed to benefit college football strength and conditioning coaches. Career long CE regimes for strength and conditioning coaches can be organized as traditional clinics and as more reform style mentor-mediated learning opportunities employed in the workplace. Further, to increase the effectiveness of the CE experience, career long involvement in longitudinal experiences (Garet et al., 2001) can provide strength and conditioning coaches with opportunities to learn about and test different strategies. Regardless of the format of CE or the content delivered, strength and conditioning coaches that engage in longitudinal learning organized around their development have the opportunity to improve practice similar to teachers (Garet et al., 2001).

In order to analyze the CE experiences of active NCAA-DI football strength and conditioning coaches, each of the previously mentioned conceptualizations will be used. Reid's quadrant theory (McKinney et al., 2005) will help organize the activities shown by the participants and the ideas by Garet and colleagues (2001) will allow the examination of the actual experiences of the participants. The exploration and analysis of CE experiences of leaders in the field can assist in the development of positive future learning opportunities for college football strength and conditioning coaches.

\section{Collegiate Strength and Conditioning Coaching}

Strength and conditioning is a multifaceted profession in which coaches must be able to handle many different duties and tasks (e.g., Brooks et al., 2000; Kontor, 1989; Massey et al., 
2004). Further, it is a rapidly progressing field, individuals share many common responsibilities and duties as well as dispositions and characteristics. Scholarship has worked to develop a picture of the field and has analyzed occupational responsibilities, professional dispositions, educational backgrounds, and suggested preparatory tracts (Brooks et al., 2000; Layden, 1998; Massey et al., 2004). As of late, scholarship has begun to examine expertise development of strength and conditioning coaches (Grant \& Dorgo, 2014; Grant, Dorgo, \& Griffin, 2014). In such a progressive field and with the large amount of contact with student athletes, the college strength and conditioning coach is in position to impact sport performance and the success of many teams.

Since 1986 when the majority of NCAA-DI schools began to employ a full-time strength and conditioning coach (McClellan \& Stone, 1986), the profession has evolved greatly. Early strength and conditioning coaches were mostly driven to guide athletes in the weight room solely with weight training techniques and simple exercise prescription (Layden, 1998). Many of these strength and conditioning coaches were hired simply from interests in weight lifting and bodybuilding. With such a specialized skill set working merely with strength development, these early strength and conditioning coaches were very narrow in their involvement in the development of athletic performance and their impact in the athletic department.

Today's strength and conditioning coaches engage in a myriad of duties ranging from traditional training of athletes to more administrative and supportive roles in the athletic department (Brooks et al., 2000; Kontor, 1989; Massey et al., 2004). Far more involved than early strength and conditioning coaches, current professionals hold responsibilities dealing with the prescription of exercise for athletes and injury prevention training protocols (Kraemer, 1990) to the supervision and administration of athletic performance budget (Martinez, 2004), campus 
recruiting, and as a liaison between the National Football League and the post-career athlete (Massey et al., 2004). As such professionals have wide ranging responsibilities and duties, many share common characteristics and dispositions that allow them to remain progressive in the field throughout their careers.

In an analysis of strength and conditioning coaches, Massey and colleagues (2004) uncovered that many collegiate strength and conditioning coaches were internally motivated and driven toward improving the performance of their athletes. Unlike other athletic coaches, it was shown that rather than entering and remaining in the field for the pure competitive drive, strength and conditioning coaches were very interested in developing their athletes on and off the field. It was also seen that most strength and conditioning coaches were very ambitious in regard to competently performing their job and the most common area of discontent involved the lack of respect from other coaches (Massey et al., 2004). As strength and conditioning coaches have become a facet of collegiate athletic departments, such dispositions indicate that many coaches have a strong interest in the athletes they train.

In addition to holding similar professional dispositions, collegiate strength and conditioning coaches exist at different professional levels at various points in their careers. In 1988, the National Strength and Conditioning Association (NSCA) worked to develop an identity for the entire field and created definitions and levels of coaching (Kontor, 1989). The different levels of full-time coaches include a strength and conditioning coach who is responsible for the development of athletic abilities and a strength and conditioning coordinator who, in addition to training athletes, is involved in collaborating with head sport coaches and the overall administration of the athletic performance program (Kontor, 1989). As coaches progress through their career, they often matriculate from being titled solely a strength and conditioning coach, to 
later as a coordinator of strength and conditioning coach. Further, for those coaches that are talented and lucky enough to remain in the field for many years, they can become head strength and conditioning coaches for a sport or even directors of the entire department.

\section{Career evolution of college strength and conditioning coaches.}

Since the inception of the collegiate strength and conditioning coach at The University of Nebraska, there have been major developments in professional standards and in practice (National Strength and Conditioning Association Professional Standards, 2009). It has been recognized that progression of the entire field of strength and conditioning is dependent upon progressive research and the dissemination and use of its findings (Gabriel, 2008). To ensure that strength and conditioning coaches have the ability to learn and incorporate progressive findings in the field, such coaches should have a strong background that prepares them for the responsibilities they will encounter once in the field.

Prior to full-time employment, many professionals engage in internship (paid/unpaid) opportunities and graduate assistantships (Mannie, 2007). It is during these early career experiences when strength and conditioning professionals often learn the fundamental skills necessary to be a successful full-time coach. Often a prerequisite to obtain more advanced, fulltime positions, internships and graduate assistantships provide young strength and conditioning coaches opportunities to develop hands-on experience and practical knowledge within the field. As strength and conditioning at the college level has grown exponentially since its widespread inception in the 1970s, internships and graduate assistantships are often very competitive and require strong educational credentials and well-rounded skills to obtain (Mannie, 2007). 
Traditionally, following a part-time graduate assistant position, a successful strength and conditioning coach will navigate a hierarchy of increasing responsibility culminating with an appointment as a leader of the strength and conditioning program (Kontor, 1989; Pullo, 1992). Although titles differ between institutions and athletic programs, the progression through the hierarchy is usually similar. Once in the field as a full-time coach, continued learning through $\mathrm{CE}$ is common and noted to improve the practices of strength and conditioning coaches and the entire field (Fekete, 1999).

As noted by Fekete, the ability to find and use new information can allow a strength and conditioning coach to be able to positively impact their athletes. Previous work has shown that a large number of collegiate strength and conditioning professionals come from areas of sport science such as physical education, exercise physiology, and kinesiology, but also from out-offield areas such as business, general education, and history (Brooks et al., 2000; Martinez, 2004; Pullo, 1992). With strength and conditioning coaches practicing in the field with such varied educational backgrounds, it is necessary to learn and progress their professional skills in less formal educational settings. As strength and conditioning coaches continue to develop abilities throughout their careers, often in the form of CE, the product of their work (athlete development) can be impacted (Gilbert et al., 2006).

\section{Associations and certifications.}

Since the development and rapid growth of strength and conditioning as a profession, there have been professional organizations, standards, and certifications created. The two main professional organizations, the National Strength and Conditioning Association (NSCA) and the Collegiate Strength and Conditioning Coaches Association (CSCCa), continually work to 
provide their members with up-to-date content and coaching resources. Each association also has certification programs that require certified strength and conditioning coaches to meet a minimum standard of progressive learning through CE.

The success of Boyd Epley at the University of Nebraska led him to develop the directory of strength coaches which later led to the very first National Strength Coaches Convention. This ultimately led to the creation of the NSCA as it exists today (The National Strength and Conditioning Timeline, n.d.). In 1988, the NSCA teamed up with Columbia Assessment Services Inc. to evaluate what content should be present on the certification exam that would be required of all its members (Kontor, 1989). Such evaluation was aimed to update and progress the organization's certification exam and to ensure that appropriate content was used to test members. The results of the study provided important information regarding the development of more appropriate testing content as well as professional standards, key definitions within the profession, and vital skills necessary to be a progressive strength and conditioning coach (Kontor, 1989). Such work laid the foundation for future efforts to standardize and progress the entire profession.

The Certified Strength and Conditioning Specialist (CSCS) certification is the professional credential of the NSCA (National Strength and Conditioning Association, 2011a). Developed in 1985, the CSCS credential was the first nationally accredited certification for strength and conditioning professionals and is obtained by passing an examination. In order to be eligible to test for the credential, an individual must possess a bachelor's degree or be of senior status in a university program and be CPR certified. Further, the CSCS credential ensures that a strength and conditioning coach meets the competency standards set forth by the NSCA 
and recognizes that an individual is qualified in the field of sport performance training (National Strength and Conditioning Association, 2011a).

In 2000, a group of collegiate strength and conditioning coaches from across the United States met in Las Vegas, Nevada to organize and create the Collegiate Strength and Conditioning Coaches Association (CSCCa) (Collegiate Strength and Conditioning Coaches Association, 2011a). More exclusive than the NSCA, full membership with the CSCCa is open only to college and professional strength and conditioning coaches.

The CSCCa exists with the ultimate goal of improving and uniting all collegiate strength and conditioning coaches. As a means of educating its members, the CSCCa offers the Strength and Conditioning Coach Certified (SCCC) credential for its members and requires the participation in a practicum experience and testing regiment. Prior to being eligible for testing, the pre-certified coach must serve an apprenticeship period under a certified coach educator currently in the field. Similar to the NSCA, the CSCCa uses the SCCC credential to ensure that strength and conditioning professionals meet the standards set forth by the organization (Collegiate Strength and Conditioning Coaches Association, 2011a).

\section{Professional learning requirements and opportunities.}

There has been significant growth in the amount of resources available to strength and conditioning coaches since the 1970s. With the development of professional organizations and a more advanced knowledge base, the philosophy driven practices of the past have been replaced with more solidified, empirically driven knowledge (Fekete, 1999). In order to continually progress the profession and ensure professionals are implementing such principles, $\mathrm{CE}$ throughout strength and conditioning coaches' careers is needed. Ongoing learning throughout a 
career can improve the efficacy of a strength and conditioning coach and can ultimately progress the entire profession (Fekete, 1999).

Both the NSCA (National Strength and Conditioning Association, 2011b) and the CSCCa (Collegiate Strength and Conditioning Coaches Association, 2011b) exist with CE initiatives that work to ensure members continually update their knowledge and are engaged as active professionals. Professional learning opportunities are offered in various forms including formalized coursework, conferences and clinics, participation on committees, publications, and through self-study. Each organization requires members to participate in order to continue to progress as individuals as well as to further strengthen the profession.

Unfortunately, it has been shown that many strength and conditioning coaches tend to rely on sources that are not empirically derived (Durrell, Pujol, \& Barnes, 2003). Coupled with the fact that collegiate strength and conditioning coaches exist with various educational backgrounds and exhibit a wide range of duties (Brooks et al., 2000; Martinez, 2004; Pullo, 1992), the foundations in which such coaches base their principles can potentially be questioned. In order to combat the limited standardized pre-professional preparation of strength and conditioning coaches, lifelong learning throughout the career of a strength and conditioning coach can be influential on their personal coaching efficacy, their athletes' success, and for the progression of the entire profession. As strength and conditioning coaches can be thought of as specialized athletic coaches, research surrounding how athletic coaches learn and develop before and during their careers can be beneficial in the prescription of CE opportunities. 


\section{CE in NCAA-DI Football Strength and Conditioning}

Since its emergence in college athletics the 1970s, strength and conditioning has had a large presence among NCAA-DI athletic programs (McClellan \& Stone, 1986). Although a relatively new professional field, strength and conditioning coaches are involved in many different elements of athletic success ranging from performance enhancement, injury prevention, and rehabilitation (Brooks et al., 2000; Kontor, 1989; Massey et al., 2004). Many strength and conditioning coaches come from a variety of backgrounds with regard to educational preparation, coach development, and playing history (Brooks et al., 2000; Martinez, 2004; Pullo, 1992). This makes the practices in the field also very wide ranging with a limited unifying framework of practice. In order to ensure strength and conditioning coaches are using empirically derived practices, professional learning in the form of $\mathrm{CE}$ throughout their career is integral. CE experiences can allow coaches to continually develop as professionals, help coaches prescribe progressive training programs, and improve the entire field of strength and conditioning.

Recently, there has been research exploring the learning of strength and conditioning coaches (Gilbert \& Baldis, 2014; Grant \& Dorgo, 2014; Grant et al., 2014; Jeffreys, 2014), however there is still limited information regarding the entire field of collegiate strength and conditioning, especially in regard to professional learning activities in the form of CE. In order to better understand the practices of NCAA-DI football strength and conditioning coaches, this study evaluated how such coaches pursued CE opportunities and how they felt about their involvement in such career-long education. Using a composite theoretical framework built from existing literature regarding the development of expertise (Abernathy, 2008; Anderson, 1982; Ericsson, 1993; 2003; Fitts \& Posner, 1967) and conceptual frameworks (Fraser et al., 2007; Garet et al., 
2001; McKinney et al., 2005) that worked to analyze CE based upon its composition, duration, and specificity to an individual's improvement, this project attempted to answer the following questions within the sample population:

1. What CE experiences were collegiate football strength and conditioning coaches engaged in throughout their careers and why?

2. What forms of CE were valued by collegiate football strength and conditioning coaches for career development and why?

3. Based on personal experiences of NCAA-DI football strength and conditioning coaches, how could CE be improved?

NCAA-DI strength and conditioning coaches operate in a field that has an ever evolving knowledge base, thus making ongoing professional learning even more important. In order to ensure that these strength and conditioning coaches are utilizing the most innovative concepts that are continually derived from research, professional learning is vital. Leading organizations in the field have taken proactive steps to ensure that certified professionals engage in $\mathrm{CE}$ throughout their careers (Collegiate Strength and Conditioning Coaches Association, 2011b; National Strength and Conditioning Association, 2011b). In order to continue to progress the field, it is imperative that more is known about how NCAA-DI football strength and conditioning coaches actually pursue such learning opportunities. 


\section{Method}

Eight $(n=8)$ NCAA-DI football strength and conditioning coaches were interviewed to explore the practices and perceptions toward CE throughout their careers. Data were collected via online demographic questionnaire and through semi-structured interview guide methods, transcribed verbatim, and content analyzed to uncover meaningful themes associated with participants' responses. To address the paucity of scholarship on how collegiate strength and conditioning coaches experience $\mathrm{CE}$ through their careers and matriculate to coaching expertise, this project sought to provide a better look at what coaches do, how they feel about their experiences, and potential areas of improvement that could positively impact future generations of college football strength and conditioning coaches. Prior to the initiation of the project, Institutional Review Board (IRB) approval was obtained through West Virginia University.

\section{Participants}

Participants in the present study included eight $(n=8)$ NCAA-DI head football strength and conditioning coaches from a variety of regions of the country and included coaches from the Southeastern Conference, the Atlantic Coast Conference, the Big Ten Conference, the Big Twelve Conference, and the Mountain West Conference. All participants were white, male, ranged in age from 36 to $60(M=48)$, and had been coaching in collegiate strength and conditioning from 10 to 33 years $(M=21.5)$. At the time of the interviews, all coaches were in charge of their respective departments yet held several different job titles. All coaches were directly in charge of strength and conditioning efforts for their football program, however several also had administrative responsibilities or additional responsibilities training Olympic sports or with academics on campus. 
Job titles varied greatly between participants and included Associate Athletic Director for Sport Performance, Assistant Athletic Director for Athletic Performance, Director of Strength and Conditioning, and Head Strength and Conditioning Coach. Participants were certified through either the National Strength and Conditioning Association $(n=6)$ or the Collegiate Strength and Conditioning Coaches Association $(n=8)$, and were employed full-time in the field for at least 10 years and considered an expert in the profession. Following Ericsson's (2003) sport expertise model, as these coaches had survived in the field for an extended period of time (10 or more years as full-time coaches), they were identified as those who had developed expertise in their trade and who could provide valuable leadership for future generations of coaches.

In regard to academic backgrounds, six of eight participants pursued undergraduate degrees in Health and Physical Education or a kinesiology based program while the other two coaches completed bachelor's degrees in fields outside of the sport sciences. In terms of graduate education, five coaches pursued master's degrees in areas of education, and one coach explored graduate education more specific to the business of sports. One participant in the study held a doctoral degree in an education related field and had explored research specific to teaching psychomotor skills.

Football strength and conditioning coaches at the NCAA-DI level are traditionally included as part of the football coaching staff whose professional livelihood hinges on the outcomes on the field on game day (Holmes, 2010; Tena, 2007). Because of this, staff turnover is often high and coaches move regularly. Some coaches can even find themselves out of the field entirely if they do not have success. These challenges make it even more difficult to remain in the field as a head strength and conditioning coach as one must be both effective in day to day 
practice as well as be a part of a successful sport program. At the time of data collection, 128 head football strength and conditioning coaches existed in NCAA-DI FBS football. Of the 128 coaches, only 73 met inclusion criteria. Eight $(10.9 \%)$ of these coaches were included in the study to create a picture of the practices of coaches across the country who have attained a head strength and conditioning coaching position, have earned accredited certification, and who have remained in the field for a period of at least ten years.

\section{Study Design}

\section{Pilot interview.}

Prior to the initiation of recruitment, a pilot interview was conducted by the primary investigator with an NCAA-DI football strength and conditioning coach who was not included in the project. The pilot interview was transcribed verbatim and reviewed by the primary investigator. This provided an opportunity for the primary investigator to practice interviewing skills, hone techniques of asking questions during interviews, and to build confidence. Additionally, as the primary investigator was a practicing NCAA-DI strength and conditioning coach at the time of the study, the pilot interview was used to explore researcher bias, and ultimately how the primary investigator would interpret responses from participants. The use of the pilot interview also allowed for the testing of the interview guide that served as the main method of data collection in the study. Following the pilot interview, the primary investigator's performance using interview questions was analyzed, and probes were adjusted to ensure proper questions were being asked and unscripted probes were prepared in order to answer research questions.

\section{Recruitment.}


During the initial development phases of the project, football strength and conditioning coaches in the Southeastern Conference (SEC) were targeted due to the success and elite status of the "football-crazed" cohort of coaches as commonly recognized by mainstream media (e.g. Branch, 2011). With this, initially, the combined use of purposeful and criterion sampling (Patton, 2002) was used in order to selectively recruit participants who met previously identified parameters of the project and their level of expertise and experience in the field of strength and conditioning. As the project progressed, there was minimal contact back from the initial email and several coaches changed jobs and were no longer available for interview. Following the project's initial guidelines, the search for candidates was expanded outside of only the SEC and convenience sampling (Patton, 2002) was employed. This process used various coaches in the field to contact potential participants that met inclusion criteria of the project.

Initial contact with potential participants was made via an initial email (See Appendix A). As needed, the same email was sent as a follow up two weeks after the initial email to potential participants that did not respond to the first contact. Within the recruitment email was a detailed synopsis of the study, purposes of and implications of research, and contact information of the primary investigator and project supervisor. If any participants had any questions pertaining to the study, they were encouraged to contact the primary investigator or project supervisor via email or telephone call.

At the time of the recruitment phase, there existed 128 universities that competed in football at the highest level of NCAA-DI. With this, it was identified that it was possible that more than eight strength and conditioning coaches would qualify for the study. It was also possible that more than eight strength and conditioning coaches that qualify would be interested in participating in the project. To manage this, the first eight strength and conditioning coaches 
who met inclusion criteria and responded to the initial email contact were used for the study.

After the eight participants were identified for the study, any remaining strength and conditioning coaches that showed interest were informed via email that the previously determined number of participants had been reached and that their interest in contributing to the project was greatly appreciated. This was present after the initiation of data collection, as three additional coaches indicated interest in participating, however as all eight participants were secured, they were thanked and notified that all candidates had been chosen.

\section{Online questionnaire.}

Following agreement to participate in the project, participants received an email with a link to Google Drive questionnaire (See Appendix B). The purpose of the online questionnaire was threefold. First, the questionnaire was used to collect more in-depth information regarding participants and questions on the questionnaire were designed to obtain more information than simple website biographies could provide. Next, questionnaires further vetted the participants in regard to meeting inclusion criteria. The questionnaire also provided first person information on the career details of the coaches and included questions pertaining to pre-career background, career progression, professional membership/membership, and involvement in CE. Finally, questionnaire data were evaluated prior to interviews and provided the primary investigator with detailed information on participants including demographic information (e.g., gender, age, race), background information (e.g., athletic background, academic background, coaching

background), and details regarding their current coaching position (e.g., job title, person to whom they directly report, years in the field).

\section{Qualitative interview guide.}


Qualitative interview guide methods were the primary means of data collection and took place via telephone call in a secure coach's office. Interviews were audio recorded and ranged on average from 45-90 minutes in length. Due to coaching turnover and the job demands of the primary investigator, telephone interviews were completed over the course of a 12 month period. Prior to the initiation of each interview, permission to record was obtained and all interviews were audio recorded and stored via Audacity 2.0.6 software. The use of this software allowed the storage and transport of audio files over the course of the project.

The use of qualitative interview-guide methods (See Appendix C) allowed interviews to be standardized yet take on a "conversation" like feel (Patton, 2002). This created a more comfortable environment between the interviewer and participant and looked to produce more valid interview responses. Interview questions were derived from current literature on expertise development, coaching education, CE, and strength and conditioning. Specific questions in the interview ranged from the exploration of general background and early learning experiences to detailed experiences in regard to CE. All interviews were conducted by the primary investigator who was trained in qualitative research through graduate level coursework and personal study of qualitative research methodology (Creswell \& Creswell, 2013; Miles \& Huberman, 1994; Patton, 2002), and was under direct supervision of an experienced senior researcher. With limited existing scholarship regarding the specific CE experiences of college football strength and conditioning coaches, the use of qualitative methodology in this project assisted in the evaluation and analysis of participants' beliefs and experiences in their natural setting (Creswell, 2009).

\section{Data Analysis}


All interviews were transcribed verbatim by the primary investigator and pseudonyms were created for all participant responses. To ensure proper interpretation, member checks with participants were conducted. Member checks involved providing a PDF copy of each transcription to each participant for review. Each participant was instructed to make any adjustments to the PDF copy as needed and was given two weeks to notify the primary investigator of any changes that needed to be made. The PDF document was sent via email, corrections were to be made via telephone call, and changes were made to the transcripts as needed. Throughout the project, every effort was made to protect the identity of all participants.

Throughout the data analysis process, there existed a method to organize and interpret data in a systematic manner. A secondary coder who was also familiar with coaching education and qualitative methods was utilized during the data analysis process. Following the transcription process, all interview scripts were read completely by the primary investigator and secondary coder and transcribed work was embedded into Microsoft Excel for organization. Following the reading of transcriptions and taking initial notes on raw data responses, conversations regarding codes and grouping were conducted to triangulate data analysis.

Raw data responses were content analyzed and from the early phases of this process, meaning units were organized (Barrosso, 1997) prior to being organized into codes or tags that existed as "tools to think with" (Coffey \& Atkinson, 1996). Later categories or sub-themes were created from similar tags. These were noted to be "internal homogeneity and external heterogeneity" (Patton, 1987). Later, higher order categories and umbrella groups were organized and represented the group on a holistic scale. During the data analysis phase, a senior level researcher supervised the entire process. 
Current literature on expertise development, coaching education, and CE was used as a theoretical framework to guide the categorization of the raw data responses from the participants in the study. Independent coders grouped similar raw data responses into meaningful units (tags) and later these tags were organized into sub-themes and later into higher-order themes. Finally, associated higher-order themes were organized into umbrella groups. As qualitative inquiry often yields data "rich in meaning" (Glaser, 2000, p. 7), the use of content analysis provided a guide in which to organize the process of extracting meaning from data. Through online questionnaire, informal interview guide methods and close proximity to data, the data analysis process evaluated participant responses to establish foundational underpinnings of what was occurring in the sample of expert strength and conditioning coaches.

The use of qualitative content analysis employed both inductive and deductive processes to both recognize past research and to generate an understanding of what is currently happening in the field. Graneheim and Lundmand (2004), note that originally content analysis dealt with the quantitative analysis of written data, but over time, it evolved to looking at qualitative data and the understanding that "reality can be interpreted in various ways and the understanding is dependent on the subjective interpretation" (p. 106). Within this process, the key aspect is the identification of the unit of analysis. In this study, the unit of analysis was the examination of what expert college football strength and conditioning coaches do for CE and how they feel it can be improved.

The use of qualitative research methods makes it important to consider the degree in which new information is being produced from responses. Saturation in qualitative research is the point when the addition of new data or information does not yield more novel trends or concepts (Glaser \& Strauss, 1967), and as Mason (2010) notes, it is the "point of diminishing 
return to a qualitative sample" (p.1). Although the addition of another response or group of data may increase the overall size of sample, its presence alone may not produce any more relevant information that is not already included in the study.

Following the sending of the initial email seeking participants for the project, a waiting period took place and allowed time for coaches who were interested in participation to respond. Later, during the interview process and analysis of the eight interviews in this project, repeating patterns and concepts pertaining to the ways coaches learn and exist in the field began to occur (e.g., the use of social learning, experience as a means of learning). This enhanced confidence that the sample size was adequate in representing a sample of the population of NCAA-DI football strength and conditioning coaches.

\section{Exposing Researcher Bias and Lens}

A critical area in the analysis of data via qualitative methodology is the view point of the researcher. This lens not only shapes the way the investigation is handled, but also influences the way that data are interpreted and reported. It is always important to consider the degree in which the view point of the researcher impacts conclusions that are reported in findings. As this can test the trustworthiness of data interpretation, Miles and Huberman (1994) assist in standardizing the process for examining data with their framework for qualitative data analysis. They break the process into four parts: 1) data collection, 2) data reduction, 3) data display, and 4) the process of drawing and verifying conclusions. It is important to note that throughout the process, different parts were overlapping and ongoing. This process was the foundation of the qualitative analysis in this project. 
When utilizing qualitative methodology, care must be taken to recognize the differences between inductive and deductive reasoning; especially during the data analysis phase. Creswell (2009) noted that during the study of qualitative analysis, there exists a medium between the development of theory (induction) and the affirmation of a previously noted idea or concept (deduction). Qualitative analysis can move toward induction or deduction, or can include a mix of both. As this study looked to identify common practices and view those learning efforts through the lens of past research, the use of both inductive and deductive analysis was used. This worked to add to the existing literature as well as to generate a better understanding of the current CE practices in the field of strength and conditioning.

During the interview and data analysis process, the primary investigator was a NCAA-DI strength and conditioning coach. Efforts were made to reduce bias and included the use of an interview-guide built from previous literature and knowledge in the area, the use of a second coder outside of the field of strength and conditioning, and the direct supervision of a senior researcher. Although bias is ever present in qualitative inquiry, the "point of view" of the qualitative observer is what drives such research (Patton, 2002). Such a lens is important as it is the unique means in which the data are interpreted and analyzed to evaluate the themes associated with the responses of the participants.

There exist two specific forms of bias that may have existed in this study: 1) Confirmation Bias, and 2) Cultural Bias. Confirmation bias, as noted by Rabin and Schrag (1999) exists when a researcher or team has a preexisting set of beliefs about a subject and uses responses from participants in a project to confirm their original opinions. Similar to Bayes Theorem, where the interpretation or analysis of an occurrence is organized and shaped by the preexisting knowledge and opinions of the researcher (Downey, 2012) confirmation bias may 
inadvertently influence a project as a researcher shapes conclusions based on what he/she already knows, or believes.

In addition to confirmation bias, cultural bias may have also been present in this and other projects that deal with researchers exploring populations where they actually work. Cultural bias has been noted to be where knowledge and behaviors of a group of people may influence the understanding or interpretation of information (Pauleen, et al., 2006). Collegiate strength and conditioning exists as a unique "culture," and a career field that is difficult to break into. As the primary researcher was a NCAA-DI football strength and conditioning coach at the time of the study, this may have impacted the way information was handled and interpreted.

In qualitative research, it is the duty of the researcher to continually strive to reduce the presence of bias. Although no qualitative work can exist with the absence of bias, efforts in this study to reduce its presence included the use of an interview-guide to guide the interview process, a second coder to validate findings during data analysis, and the ongoing supervision of a senior researcher. 


\section{Results}

Current literature on expertise development (Abernathy, 2008; Anderson, 1982; Ericsson, 1993; 2003; Fitts \& Posner, 1967), coach education (Abraham \& Collins, 1998; Cushion et al., 2003; Merriam et al., 2007; Rynne et al., 2010; Trudel \& Gilbert, 2006) and CE (Fraser et al., 2007; Garet et al., 2001; McKinney et al., 2005) was used to guide the categorization of the raw data responses from the participants in the study. Analysis produced six umbrella groups that related directly to the research questions and described the CE dispositions of NCAA-DI strength and conditioning coaches. Umbrella groups (See Table 2) included: 1) Personal CE practice and engagement in learning, 2) Values toward coach learning and active leadership behavior with CE, 3) Individual barriers to CE, 4) Organizational barriers to CE, 5) Suggestions for individual CE enhancement, 6) Suggestions for organizational enhancement of CE. The sub themes and higher order categories that created each of the umbrella groups are discussed in depth in the following sections.

In addition to the results directly related to what collegiate strength and conditioning coaches do for $\mathrm{CE}$, there were also responses related to the backgrounds of coaches that may provide additional insight into why coaches choose and value specific learning experiences. Although the responses do not relate directly to the research questions, they aid in the understanding as to why coaches explore specific forms of learning through their careers. One additional umbrella group emerged: Impact of personal backgrounds on CE pursuits. This umbrella group related specifically to the pre-professional experiences of the participants and provided incite into how coaches developed an understanding of the profession and ultimately professional learning. 


\section{CE Practices of NCAA-DI Football Strength and Conditioning Coaches}

\section{Personal CE practice and engagement in learning.}

The first umbrella group that emerged from the data was Personal CE practice and engagement in learning. This was referenced by all eight participants in the project. This umbrella group was comprised of five higher-order categories: 1) Learning through social connections, 2) Active involvement in self-study, 3) Experience as a vehicle of learning, 4) Deliberate learning at conference, and 5) Enrollment in formal graduate education. The higherorder categories Learning through social connections and Active involvement in self-study were the most commonly noted in the responses and were reported by all participants.

\section{Learning through social connections.}

The Learning through social connections higher-order category contained four subthemes including Communicating with peers, Learning from more capable others, Visiting other strength and conditioning programs, and Learning from athletes. Of these sub-themes, Communicating with peers and Learning from more capable others were recognized by all eight participants in the project.

For the sub-theme Communicating with peers, coaches responded that through the use of in-person conversations and phone calls, they felt it was not only important to stay in touch with their colleagues, but also look to learn from them. Trust was a key factor when talking with colleagues for one coach in his raw data responses as he noted, "Talking to certain guys that I trust, I think that again, I respect and see what things they are looking at." Further, another coach noted the importance of building a network to learn from. He noted the need to "connect 
yourself as a coach to a group or a network of colleagues and, the greatest thing about that is, you're going to begin to develop relationships."

Also, all coaches in the project noted looking to other elite coaches to continue to learn. Raw data responses for Learn from more capable others was seen in the comments from one coach as he noted, "You know I think success leaves tracks and I've always tried to just go to people that were probably one, smarter than I was, and two, they'd been kind of longer and had been more successful." Another coach noted that when learning from peers, it is even beneficial to look outside the field of strength and conditioning. He noted his experience in the following:

The head basketball coach my first four years, and I probably learned as much from him early on as a young coach, because he was so hard on his staff, and the players, and I learned at a young age that you had to have ice cold veins if you really wanted to survive in this profession.

Additionally, five participants noted the importance of Visiting other strength and conditioning programs for their continued advancement in the field. This was similar to other communication with peers, except that it was noted that through visiting different departments, coaches can tangibly see both the positives and negatives that occur within strength and conditioning departments. Finally, for the sub-theme Learning from athletes, one coach noted that through his career, he learned from many athletes that he directly worked with at various experiences during coaching and in different interactions.

Learning from social connections and other individuals in the field was noted by all participants in the study as a means of CE through their career. The levels of engagement between participants differed as some coaches reported looking to intentionally learn directly 
from their superiors, while others looked outside of the field of strength and conditioning to absorb different learning opportunities. While all coaches in the project noted ongoing communication with other members in the field, it must be noted that this was not the only form of social learning that was reported. One coach noted a significant learning experience in his career as he directly observed a head sport coach that he directly worked with and felt as though much of his philosophy was built on what he viewed as a member of the support staff. Another coach noted that when he looked to learn from his peers, he only looked to coaches that he viewed as better than him, or that he knew and truly trusted. Coaches also indicated that they learned from social connections outside of the coach to coach relationship. One coach that worked at a university with perineal athletic success noted how he learned a lot from the close proximity that he had with elite professional athletes that would return to his weight room to train during their offseason.

\section{Active involvement in self-study.}

Active involvement in self-study was a higher order category that included five distinct sub-themes. These included: 1) Research through exploring practices of opponents (62.5\%), 2) Reading to improve practice (62.5\%), 3) Learning through multimedia (62.5\%), 4) Writing for journals/books (25\%), and 5) Use of NSCA online quizzes for continual learning (12.5\%).

The most commonly noted forms included Research through exploring practices of opponents, Reading to improve practice, and Learning through multi-media. Each of these subthemes were reported from five $(62.5 \%)$ participants. Raw data responses for Research through exploring practices of opponents included comments related to personal research endeavors to 
deliberately improve professional practice. One coach, in particular, noted his day to day routine for learning outside of the normal working day:

I continue education all the time, I go to bed every night, and the last thing I do is probably check about five different websites or I google strength and conditioning, or I google winter strength and conditioning program. And I'm lying in bed until like 10 o'clock at night and I'm on the iPad um trying to figure it out what others are doing.

For the Reading to improve performance sub-theme (cited by 5 participants), one coach stated, "I always like to say, leaders are readers." Further, one coach noted his planned daily readings. This raw data response detailed his efforts to stay current on content and to always be learning. He noted:

I spend at least an hour per day, in reading in either the technical side of the field, either the psychological/motivation if you will, and then just outside things, I try to read, you know biographies, historical, it doesn't have to be anything really related sometimes to strength and conditioning or our field, but some kind of some kind of outside perspective to get you know different viewpoints, different ideas and how then they can apply to what we do.

For Learning through multimedia, participants referenced the differences between their past experiences with learning from traditional journals and the current structure of online learning opportunities. Multimedia platforms used by coaches included, "watching a DVD, watching a video, or watching a podcast, or whatever the hell they call it."

The sub-themes Writing for journals/books and Use of NSCA online quizzes for continual learning were recognized by $25 \%$ and $12.5 \%$ of participants respectively. The coaches that 
reported Writing for journals/books cited an interest to assist other colleagues in the field by sharing information and to "create a path" for developing coaches to follow. One coach in the project noted the use of NSCA online quizzes for continual learning.

\section{Experience as a vehicle of learning.}

The higher-order category Experience as a vehicle of learning had sub-themes including Learn from day-to-day experience, Learn through personal internship experience, and Teach/Instruct classes. The Learn from day to day experience sub-theme was reported by all eight participants. Coaches noted the experience to be important and commented "learning in the trenches," and "thrown in the fire" in raw data responses to emphasize the importance of experience as a learning medium. Raw data responses included comments pertaining to the learning opportunities that exist during day to day experiences while coaching. Additionally, another coach noted that you can also learn from negative experiences and from his point of view, "there were too many wrong people there. But I didn't interview them to find out what they wanted and it didn't work out so."

Finally, within the Experience as a vehicle of learning higher-order category, two participants noted responses in the Learn through personal internship experience sub-theme and one coach cited teaching graduate level coursework as a means to remain current in CE. Two coaches noted positive internship experiences that were influential on their careers. Both of these coaches noted that because of their personal experiences with their internship, they also used such programs in their staff to educate and groom developing coaches that may join their staff down the road.

\section{Deliberate learning at conference.}


The higher order category Deliberate learning at conference was organized with four sub-themes. The most commonly referenced sub-theme was Formal learning at conference and was noted by six participants $(75 \%)$. It included raw data responses in regard to how often a coach should go to conference. One coach noted, "I think it's important to go to the conferences, and I don't mean every year, but I don't know if it's every one out of three years, I don't know what the right ratio is, but the good thing about the conference is, you get a chance to hear good speakers, there's no doubt about that." The sub-theme Conference networking (cited by 3 participants) was made up of raw data responses regarding visiting with colleagues in formal and informal type settings. One coach noted, "I look forward to the convention every year, it's just to sit around and shoot the bull with people about what they are doing with training," while another coach says, "I think getting out going to clinics, and you know again, you want to go to conventions, go out with a buddy, go have a beer, talk about stuff from elsewhere."

Active involvement in administering or operating conference was cited by one participant and was comprised of raw data responses that included his experience in hosting a regional coaching clinic and the impact that he felt it had on developing coaches. During his involvement, he was a part of a committee that chose speakers, work organized to manage testing for coaches looking to obtain certification, and a part of the peer review process for various publications that would come from scholarship around the conference.

Finally, Learning from vendors was cited by two participants. These coaches noted the learning that can come from conversations with vendors at conferences. In regard to learning through vendors, one coach noted, "you can also get your hands on and talk to other people through vendors, through the vendors. And that's a way to educate yourself." Another coach discussed how his strategically planned interactions and relationships with vendors not only 
allowed him to learn about new products on the market, but also provided information on different opponents in the field. Finally, he noted that as many vendors are often former coaches themselves, he felt as though he could learn from their unique perspective as a coach turned merchant.

\section{Enrollment in formal graduate education.}

The last higher-order category in the Personal CE Practice and Engagement in Learning umbrella group included Enrollment in formal graduate education (cited by four coaches). This higher-order category included three sub-themes that included: Engagement in master's degree program, Engagement in doctoral degree program, and No involvement in formal grad program, but active coursework. Of the three sub-themes, the most commonly noted was Engagement in master's degree program with 50\% participants reporting. Major raw data responses within this sub-theme included comments regarding skills and knowledge developed through direct involvement in graduate education.

One coach specifically discussed that he developed management and guidance skills during his graduate school experience and stated that he felt these skills may be as important, or possibly even more important than the actual sport science content he learned training to be a strength and conditioning coach. He noted, "I used, those people skills are much more handy than any of this science stuff that I learned or attempted to learn when I was in school with that stuff."

Engagement in doctoral degree program was only mentioned by one participant in the study and included raw data responses regarding his interest to use his degree to formulate a coaching education program to serve developing coaches. The last sub-theme, No involvement 
in formal degree program, but active in coursework also only had one response. The coach cited changing coaching positions as a reason he had never finished a graduate degree. He noted, "I have enough hours for probably two masters degrees, but I only stayed the university one year at each one of those places."

\section{Values Toward CE of NCAA-DI Football Strength and Conditioning Coaches}

\section{Values toward coach learning and active leadership behavior with CE.}

The second umbrella group, Values toward coach learning and active leadership behavior with $C E$ existed with responses from all participants in the study. This umbrella group was comprised of four higher-order categories. These included: 1) Responsibilities and skills of coaches for CE learning, 2) Create nonformal CE situations for staff, 3) Active engagement in professional organizations, and 4) Attitudes toward professional organizations. The most commonly noted higher-order categories were Responsibilities and skills of coaches for CE learning (100\%) and Create nonformal CE situations (87\%).

\section{Responsibilities and skills of coaches for CE learning.}

The higher-order category Responsibilities and skills of coaches housed six unique subthemes. These sub-themes directly supported different coaches' opinions as to the responsibilities of coaches, especially in regard to their continued learning. Responsibility for personal growth was noted by six (75\%) coaches as a duty of coaches. Raw data responses supporting this sub-theme included comments on how regardless of age, coaches must consistently be active in looking for new learning experiences. One coach noted, "older guys need to be open to new ideas, more efficient ways to train, and not be closed to subjects that they think are the best." 
The next sub-theme that was represented in the data was Actively seeking to improve personal practice. This sub-theme was noted by five $(62.5 \%)$ participants in the study. Raw data responses for Actively seeking to improve included the pursuit of learning by looking at new content and new methods for learning and regardless of the situation or medium of learning coaches should be engaged in some sort of learning throughout their careers. One coach noted it was important to find, "certain areas that we want to investigate more." Additionally, another coach noted:

We have a quest to do a better job for our athletes to provide the best program that we can with what we have, you know to help them reach a potential that I think that you have to, you always have to look at what can we do better?

Thinking like a teacher and Understanding the importance of education were sub-themes that were discussed by two (25\%) of participants. Of the participants reporting, connections between teaching and coaching were made as was the impact that their involvement with teaching had on the way they viewed learning and education. In the Thinking like a teacher subtheme, participants noted how their backgrounds in teacher education shaped the way they think, and more specifically, one coach said his background in teaching helped him develop, "patience and persistence." Both, he noted were skills beneficial to coaching athletes.

One coach noted his views in the Understanding the importance of education sub-theme by stating that the atmosphere around his staff must be one that is conducive to learning. In regard to the situation that was created around his staff, he noted, "we have an environment that encourages education or continuing education." From this positive learning experience, coaches can continue to learn and grow. 
The sub-theme Possessing a growth mindset was reported by two participants, and raw data responses charged coaches to have a fire inside them to continue to learn and according to one response, "learning to not paint yourself in a box of philosophy." One coach mentioned this explicitly by noting, "I'm trying to more open minded and learn." Another coach stated this by noting that regardless of how much a coach may know, he cannot ever quit looking to learn. He challenges coaches that if they do feel as though they don't need to learn, it may be time for them to switch professions.

Being open minded enough to understand that you get to a certain, you get to a point where you think you know the things, you know the answers, and you don't have any questions, its probably time to, you know find something else to do.

As it has been recognized that coaches must engage in active learning, it is also noted that coaches must Rest the ladder on the right wall and learn from legitimate sources. This was noted by two different participants and was represented in raw data responses from one coach that noted the importance of filtering content and not falling for various fads that may exist. He noted, "So, the point of that is, just because there's fads and they're sexy, doesn't mean that it works." The same coach also continued by noting, "we are buried under the weight of information which is being confused with knowledge. Quantity is being confused with abundance, and wealth with happiness."

Another coach also discussed the importance of using the right sources to learn new content in the following comments: 
So when you get to the top of the ladder, you realize that you are leaning up against the wrong building. In other words, you need to have your ladder attached to a building that is based on solid principles that isn't going to change.

\section{Create nonformal CE situations for staff.}

The higher-order category Create nonformal CE situations for staff was comprised of six sub-themes. The largest sub-theme group included Assist staff in learning and was comprised of responses from five $(62.5 \%)$ participants in the project and was built from responses regarding helping coaches pursue CE experiences by way of paying for credentials, membership, or different learning experiences. These responses pertained directly to the coaches' involvement in assisting their staff in CE experiences.

The sub-themes Have professional CE requirements for staff and Have organized learning curriculum for staff included responses from four (50\%) participants in the project. For professional requirements, coaches noted several things including mandatory conference attendance, the maintenance of certification, and required reading. One coach, even noted that he requires that his staff read daily. He doesn't care when they do it, but, "they are mandated to, take thirty minutes out of their day, whether they come in at 4:00 AM or they stay "til 8 PM."

Have organized internship program was a sub-theme that had responses from three participants and was comprised of raw data responses that involved presenting to staff and researching outside content to bring back to other members of the staff. One coach noted specifically that he uses interns to evaluate the current operations of the staff. This not only provided an evaluation system, but existed as a checks and balances system for him to see what his crew of interns are learning. He noted: 
We make our interns evaluate our program with their young eyes. So they have to give a presentation, a PowerPoint presentation on what they are learning, what they deemed as what they think is important. And its fun to see because they've actually picked up on what I've wanted them to, or they've picked up on something that we've neither realized that we are making important, they pick up on. So that really is like a, you're getting a lot of self-evaluation from multiple people.

The sub-theme Have organized learning curriculum for staff contained raw data responses that included on the floor coaching and specific meetings designed for learning. One coach discussed his meetings for his staff that is designed around a curriculum that is based on different aspects of the coaching profession. One coach offered thoughts regarding the contents of his staff development curriculum:

...certain topics and you know, discussing things, discussing trends, you know, discussing you know, what we think is you know, how is the profession get involved, what is the next step, so how can we improve our program, what communication?

Two coaches were included in the sub-theme Mentor staff to hire later and discussed how they used their coach development program in their staff to grow young coaches with the hopes of hiring them full-time later in their career. One coach noted that he relied on interns to learn and grow so that he can hire them later in his career. Only one coach mentioned Minimal involvement in staff development. Although this coach did not note specific involvement in the development of his staff, it should be noted that he recognized that his staff was contained in a small office space and that informal learning was always taking place. In total, seven of eight coaches reported that they promoted an environment of learning for coaches on their staff while 
four of the eight coaches noted that they had an organized program or learning requirements for their staff.

\section{Active engagement in professional organizations.}

The next higher-order category, Active engagement in professional organizations was comprised of five sub-themes. These sub-themes include 1) Active as senior staff in organizations, 2) Maintain personal certification, 3) Dual membership, 4) Contributed to journal or organizational periodical, and 5) Assist with collaboration between organizations and NCAA.

The most common sub-theme was Active as senior staff in organizations. Five coaches (62.5\%) discussed Active as senior staff in organizations. In regard to being active members of leadership in professional organizations, several coaches alluded to their interest in being involved and one coach specifically mentioned that "if I can have a hand in something, I'm going to." Other raw data responses included responses regarding involvement in various roles in the organization including leadership positions, serving on committees, and even hiring speakers for conference. This was in addition to the four coaches that discussed simply the act to Maintain personal certification.

The sub-theme Contributed to journal or organizational periodical contained responses from two participants. This sub-theme was comprised of raw data responses showing an interest in contributing to the current body of knowledge in the field, and an interest in being involved past simple membership. Only one coach provided responses in the Assist with collaboration between organizations and NCAA sub-theme, however his responses noted a heavy involvement in the actual rules and regulations that exist for college strength and conditioning coaches today.

\section{Attitudes toward professional organizations.}


A major difference noted between coaches in the study was how they spoke about the different professional organizations in the field of strength and conditioning. Coaches in the project discussed involvement in both the National Strength and Conditioning Coaches Association and the Collegiate Strength and Conditioning Coaches Association. While some coaches noted primary involvement in a single organization, several also discussed the benefits of holding dual memberships. The higher order category Attitudes toward professional organizations was identified by four different coaches and was supported by five sub-themes.

One coach noted that there were Specific differences between organizations and noted this in raw data responses, these differences were especially related to the certification process; especially in regard to an internship component. One coach noted, "the Collegiate Strength Coaches Association has got the mentor program that I think is really good." Further, another coach noted that between the two organizations, there exists clear differences. He noted:

You know the NSCA is fantastic with everything they do, but you know they try to do a lot of things for a lot of people. They're helping personal trainers and the special populations and you know the TSAC stuff and all those fitness professionals and performance professionals in addition to any coach, high school, collegiate, and professional level and that's just a lot of bases they are trying to cover. Whereas the Collegiate Strength Coaches are locked in on just what the collegiate strength coaches can do.

It was also noted by one coach that Both organizations provide educational resources and that the primary differences exist with the types of CE provided through the year. Regarding which organization was most beneficial for professional growth, all responding participants 
noted that both provide positive, yet unique experiences. One coach discussed this further in the following comments:

For me to just blanket out that one is better than the other, I can't do that, it comes down to what the coach wants to do, what direction they want to head... as to which experience is going to suit their needs better.

One coach in the project noted that although important, certification should not end learning and this was identified by the sub-theme Certifications should not terminate learning. Raw data responses included comments including, "Education is a lifelong experience," and even more specifically, coaches note that they do not hire coaches simply off certification, but for their abilities as a coach. One coach mentioned this with the following, "I care about what can you do, and how do you get across to those kids."

One coach noted that certification has been evolving since its inception. The sub-theme Certification processes ever evolving since their inception embodies this and is acknowledged through discussion of where testing and certification was during the early days of the field as compared to today's situation. One coach mentioned that the test has become much more difficult. He noted, "they've really made that certification test a lot more difficult that probably the way it was when I took it in '06."

\section{Ways to Improve CE}

\section{Individual barriers to $\mathrm{CE}$.}

The first umbrella group pertaining to improvements related to CE included Individual barriers to CE. Within this umbrella group existed three higher-order categories: 1) Budget 
differences between schools (75\%), 2) Unity within the Field: Bring professionals together (50\%), 3) Time Constraints (25\%).

\section{Budget differences.}

The Budget differences higher order category was the largest and most recognized category (cited by six participants) and was comprised of only one sub-theme: Different schools have different resources for staff. This sub-theme was cited by six coaches and was built with raw data responses associated with budget, opportunities for $\mathrm{CE}$, and support from administration for staff growth. Specifically, coaches noted that they work to provide their staff with resources to grow, and one coach noted, "you know so I think that's something that if you can do that budgetarily wise that is certainly something you do." In regard to working to attend conferences annually, one coach noted that it can be difficult for smaller universities or for coaches with small salaries to realistically attend conference each year. He noted, "its going to be very tough for a coach from a small college to go every year, and if he's not making a lot of money anyway and if the school won't pay for it, that's pretty tough."

\section{Unity within the field: Bring professionals together.}

The higher-order group Unity within the field: Bring professionals together contained one sub-theme: Coaches should collaborate with colleagues during learning and practice (cited by four participants). Raw data responses included comments from coaches including the following:

I think, you know what the biggest thing that I really think that needs to happens is that we need to unite as a coaching profession. I feel like we're all kind of doing our own thing, but we're really not united. 
Essentially, responses emphasized the importance of different professionals in the field working together to learn and grow from one another throughout their careers. Even further, these coaches noted the unity that exists in the field of Athletic Training. One coach noted this by stating, "but just really just as a props to the athletic trainers, they have got their stuff together. And they're united, they're working together, they're collaborating for their organization."

\section{Time constraints.}

The higher order category, Time constraints was only noted by two participants in the study, but was impactful in illustrating the nature of the business of strength and conditioning. This included one sub-theme, Limited time to learn due to demands of job, and painted a picture of the actual time demands that a college football strength and conditioning coach faces. This was colorfully illustrated by one coach when in regard for reading and self-study, he stated, "who has the time?"

\section{Organizational barriers to CE.}

The second umbrella category, Organizational barriers to $C E$ pertained to specific barriers that curb CE effectiveness and is organized with one higher order category, Unity within the field: Bring organizations together. Additionally, there was one sub-theme, Organizations must create unified body of practice to enhance learning (cited by three coaches in the project), that was comprised of raw data responses pertaining to the lack of a unified governing body and system of learning for coaches. As there exists two completely independent organizations in the field (NSCA/CSCCa), participants in the project noted there should be efforts to merge the overall goals and directions of everyone involved. More specifically, regarding the focus of each 
organization, one coach noted, "one's too specialized and one's too broad based," and another coach noted that as organizations have continued to grow, they have become "watered down." Finally, another coach noted that the professional organizations need to exist with, "one heartbeat."

\section{Suggestions for individual CE enhancement.}

All participants gave responses in the Suggestions for individual CE enhancement umbrella group. This umbrella group included three higher order categories: 1) Be more professional in learning and in practice, 2) Differentiate learning experiences, and 3) Identify and learn important skills and knowledge. The most noted higher order category was Be more professional in learning and in practice and was cited by all eight participants. Both Differentiate learning experiences and Identify and learn important skills and knowledge were also important and were cited by six and three coaches respectively.

\section{Be more professional in learning and in practice.}

The most noted higher order category, within the Be more professional in learning and in practice higher order category, existed with four sub-themes. The largest sub-theme in this higher order category existed with Understand evolution and future directions of the field. This sub-theme was referenced by seven participants with raw data responses that included comments on how coaches have evolved since the beginnings of strength and conditioning. More specifically, one coach noted, "I think you will see strength coaches become more of a, more of a health pro as opposed to that grinder, or that meathead, or anything whatever connotation that you want to throw out there." 
Responses also indicated the need for strength and conditioning coaches to become more professional in their day to day practice and in the way that they learned throughout their careers. Participants noted that often times strength and conditioning coaches are isolated in the weight room and do not seek out experiences or even interactions with other professionals in the athletic community at a university. Further, at least one participant noted that some coaches, "just want to coach." This was noted among participants in the study to be a potential issue for the overall progression of the field.

The development and growth of the internet has also significantly changed the way coaches learn. In the past, one coach noted, "whenever I was doing my education stuff, you had to read the journals or you had to go to a library and look up research and find out what to get and where to get it." Now, he continued, there is so much information readily available, it is virtually "at your fingertips when you are sitting at your desk now."

The sub-theme Assist in development of younger generations of coaches was referenced by two coaches and was supported with raw data responses like comments by one coach that older coaches should work on "putting, young coaches in those positions, as best we can, to get that experience." As another coach stated, being a good role model and providing advice such as, "if this is really something you want to do, you're going to have to dedicate yourself to it and then, and and in all respects."

Finally, the sub-themes, Have skills to transition out of the weight room late in career and Be capable of handling administrative duties were recognized by one participant each. Raw data responses in these sub-themes included details regarding being able to handle tasks outside of the normal realm of strength and conditioning and the importance of being able to work in 
both coaching and administrative situations. Specifically, when talking about the late stages of learning in a coach's career, one coach noted that coaches need to learn skills outside the realm of traditional weight room material. Looking back at his career of learning and practice, he noted, "are we doing a good enough job where an old strength coach, like myself, who are on the verge of trying to transition out of their profession, what's the next step?" When comparing the field of strength and conditioning to the athletic training profession, one coach noted that due to their administrative skills, athletic trainers have "positioned themselves in these higher roles in the university setting than many strength coaches."

\section{Differentiate learning experiences.}

The next higher order category was Differentiate learning experiences (cited by six coaches) which existed with three sub-themes: 1) Differentiate learning experiences throughout career, 2) Do not rely solely on conference attendance for CE, and 3) Organizations should offer and accept variety of CEU opportunities. The most noted sub-theme was Differentiate learning experiences throughout career and entailed comments charging coaches to explore a variety of different learning experiences in the form of content and delivery. When in pursuit of different educational experiences, coaches noted, Do not rely solely on conference attendance (cited by one participant) for continual learning. Additionally, one coach noted that the organizations that provide CE experiences should actively strive to offer and recognize different learning experiences for CEU credit and career-long learning.

For the sub-theme Differentiate learning experiences throughout career, raw data themes pertained to how coaches should explore a variety of different CE experiences throughout their career. Closely related was the sub-theme Do not rely solely on conference attendance for CE. 
One participant noted that coaches should not only rely on conference attendance for CE learning and that he would "hate to see them box themselves in with the conference." Further, for the sub-theme Organizations should offer and accept a variety of CE opportunities, one participant specifically stated that organizations, "need to expand a little bit more into some alternative methods whether it be, teaching classes, just whether just doing clinics, getting credit for that."

\section{Identify and learn important skills and knowledge.}

The higher order category Identify and learn important skills and knowledge was referenced by three different coaches and was comprised of two sub-themes. The first subtheme, Be aware of learning style and know your personal needs (cited by one participant), was

supported by raw data responses that included specific questions to coaches and included, "what are your passions? What are your skill sets? What are the gifts and talents that you have?" The Coaches must have general pedagogical skills (cited by three participants) sub-theme was comprised of raw data responses that noted that although specific knowledge was important, general teaching skills are necessary to maximize coaching practice. What is troubling, as noted by one coach, "we don't train teachers anymore."

\section{Suggestions for organizational CE enhancement.}

The final umbrella group Suggestions for organizational CE enhancement was comprised of two higher order categories. These included 1) Lack of a singular organization of standardized education and 2) NCAA rules may inhibit learning of future coaches. Each of which was noted by three participants in the project.

\section{Lack of a singular organization or standardized education.}


Within the higher order category Lack of a singular organization or standardized education was represented with two sub-themes. The first sub-theme There exists minimal collaboration between organizations was represented by the responses of three $(37.5 \%)$ different participants in the study. In the raw data responses, coaches noted that they felt the field needs to, "probably being just a little bit more you know stronger as a group or united as a group and and helping to mold what we do a little bit more." One coach went as far as to state that he did not feel as though the two organizations would merge, but there would be "some joint efforts and I think the health and safety initiative of the collegiate arena is going to be the way to do it, and maybe even the professional arena."

The second sub-theme, Holding a competitive edge limits sharing between coaches was noted by one coach in the project and was also noted to be a major barrier to the current structure of CE. Specific examples of this were seen from comments pertaining to the lack of collaborating with other professionals in the field because they are often "tied directly to wins and losses of those programs."

As seen in the following comments, it was noted that it is often frustrating when professionals don't return phone calls:

I just think that overall as a profession there should be more openness when it comes to helping other people let other people know what they are doing. You know, I got to chuckle sometimes when people won't give out a suggestion or a work out that you end up calling about or people don't return your phone call, you know there's some of that out there and you know that's just always amused me.

\section{NCAA rules may inhibit learning of future coaches.}


In the final higher order category NCAA rules may inhibit learning of future coaches (cited by 3 coaches), there existed two sub-themes derived from participant responses. The 5coach rule limits FBS programs to only 5 S\&C coaches sub-theme was noted by three participants in the project. More specifically, these coaches stated, "and now we've been limited with the number of positions we can have, uh, by NCAA rules and regulations. It's made it hard. And uh, that's one thing I think we can do a better job at too." Further, in regard to the constraints placed on learning from the coaches, the sub-theme Coaches must be certified to become full-time (cited by one coach) forces developing coaches to seek certification status and early learning in their career. Finally, it was noted this may place added constraints on developing coaches in a field that is already saturated and limited in the amount of employment opportunities that exist.

\section{Impact of Personal Background on CE Pursuits}

In addition to content directly related to the research questions of the study, participant' responses also exposed different areas of their personal backgrounds that may be influential on their career-long pursuit of CE. These responses are contained in the umbrella group Impact of personal background on CE pursuits. These included two higher-order categories: 1) Proximity to sport and training and 2) Academic background and proximity to education. All participants in the study produced responses regarding elements of their background in regard to their involvement in sport and in education.

\section{Proximity to sport and training.}

In the higher-order category, Proximity to sport and training, there existed four subthemes: 1) Early athletic opportunities, 2) Proximity of a role model, 3) Involvement in 
collegiate sport, and 4) Overcoming obstacles. The most commonly mentioned sub-themes included Early athletic opportunities and Involvement in collegiate sport which were noted by all participants. Further, half $(n=4)$ of the coaches mentioned the Proximity of a role model that pushed them into sport and later coaching.

For the sub-theme Early athletic opportunities, all coaches in the project indicated that their initial interest in the field of strength and conditioning began at a young age when they were involved in youth sport and other physical activities. Raw data responses from the coaches included comments pertaining to involvement with physical education activities, youth/adolescent sport, and unstructured play. In regard to his early experiences that played a role in his interest in learning to become a strength and conditioning coach, one coach noted, "I guess the very first seed planted was just being a kid when I was gosh, in my single digit years, and then just kinda keeping up in PE classes and going through training for school ball."

In addition to the proximity to opportunities to train and play was a factor as was leadership in the form of a mentor. This was seen in the sub-theme, Proximity of a role model which was discussed by four of the participants in the study. This figure was identified as a person who assisted in their developmental path as an athlete, and also assisted in setting the foundation for their initial philosophy toward sport, coaching, and how they could exist in the field. In regard to his relationship with his father as a role model, one coach noted, "dating back to like 7th or 8th grade, or earlier, I was just always fascinated with muscles and strength training, my dad was a marathon runner. In terms of training, ran a couple marathons, I watched him train." Additionally, two participants in the study noted ongoing communication with their early mentor even after they were employed in the field as a strength and conditioning coach. 
All participants in the study discussed their Involvement in collegiate sport in their responses. Five coaches provided responses regarding their involvement in NCAA athletics (4NCAA D-I, 1-NCAA D-III) and three coaches noted participation in non-NCAA activities (i.e., Olympic weightlifting, powerlifting, and boxing). From the responses of coaches reporting involvement in collegiate sport, one coach noted how he developed a heightened interest in the field of strength and conditioning by watching how the program he participated in was managed by his coaches. Another coach noted that during his college athletic experience, he was exposed to a lot of different training modalities that he had not used before. This pushed his interest even further, and as he noted, "And just loved the weight room in college, and that took over and carried over until I felt like I wanted to it professionally for a career.” Collegiate experiences exposed the aspiring coaches to competitive experiences and placed them in close proximity to elite coaches and decisions pertaining to high level sport.

Overcoming obstacles and working through physical weakness was also discussed as a major impetus for an interest in the field of strength and conditioning. One participant offered his story on how his early limitations and exclusion from team training pushed him to consistently workout and improve as an athlete. More specifically, he noted:

I caught the bug I call it... in ninth grade, I was very undersized, as a football player and they actually put us in lifting groups in high school, when I came out of ninth grade going into tenth, and I was in, I was so weak, I was in the last tier of lifting groups of guys that they didn't actually have room for us, they put us out in the hallway. 
Such challenges pushed him to engage in additional training experiences and to seek out learning so that he could improve as an athlete. This essentially began his early involvement in training, and heightened his desire to pursue learning about the body and improving physically.

\section{Academic background and proximity to education.}

In the higher-order category Academic background and proximity to education, there existed two sub-themes: 1) Pre-professional education and 2) Proximity to education. All coaches discussed specific elements of their Pre-professional education that were important for their development as a coach and which were influential on their learning tendencies. Further, two coaches noted close Proximity to education in the form of family members that were teachers.

All participants noted specific Pre-professional education that was influential on their primary development as a coach. Some learning experiences were directly related to the field while other coaches mentioned out of field experiences that shaped the way they viewed sport, coaching, and learning in the field. One coach discussed how his background as a teacher was what guided his practice in learning as a coach. He noted:

By trade, I'm a teacher, that's what I was trained to do. So, my teaching background, the pedagogy of how we teach, and that, those type of things of, that's the type of things that I try to become better at as a teacher. Going back to my background in organization, lesson plans, developing curriculum, so I look at those areas a little bit more, you know and like I said look at the other areas, try to pick out an area that I need to get better at and try to say that I'm going to immerse myself in that. 
In addition to coursework in education during their college experience, two of the participants noted the Proximity to education through their lives. One coach discussed the impact of growing up with a mother who was a teacher and living with a wife who was also a teacher. In regard to his experience with education through his life, he noted, "My mother was a school teacher, my wife is a school teacher, I got my education degree..." Another coach also talked about his wife as a school teacher and the "atmosphere of learning" that existed in their family household. The raw data responses of these coaches clearly indicated that education played a role in their lives both inside and outside of professional practice. 


\section{Discussion}

Currently, there exists no formal path to gain employment and to pursue expertise for NCAA-DI head football strength and conditioning coaches. Further, there are limited definitions for what expertise in strength and conditioning coaching truly may entail. Finally, with such variance in backgrounds (e.g., athletic, academic, exposure to coaching) prior to full-time employment, strength and conditioning coaches exist with minimal standardized practices. This makes CE vital for not only the progression of individual coaching effectiveness, but also for the progression of the entire field of strength and conditioning professionals.

This project evaluated participant responses through a composite theoretical framework that was developed from existing literature on expertise development (Armour et al., 2009; Ericsson, 1993; 2003; Ericsson, 2008a; Fitts \& Posner, 1967; Schempp et al., 2006), CE (Birman et al., 2000; Cervero, 2000; Garet et al., 2001; McKinney et al., 2005), and the education of athletic coaches (Cushion et al., 2003; Mallett et al., 2009; Trudel \& Gilbert, 2006; Werthner \& Trudel, 2006). Specific theories and constructs involved in the development of this composite lens include Ericsson's theory of expertise and deliberate practice (1993), Reid's Quadrant Theory for CE (Fraser et al., 2007; McKinney et al., 2005), and Garet and colleagues (2001) analysis of CE regarding structural and core features. Coaches were viewed as educators (Jones, 2006) throughout the study, and scholarship regarding expertise development and teachers' use of $\mathrm{CE}$ was used to evaluate how strength and conditioning coaches approach learning through their careers.

It is interesting to consider how the different developmental paths of the coaches in the study may have been influential on how they viewed learning through their career and their 
overall involvement in CE. While Lyle (2002) notes that coaches should explore a variety of different learning experiences to develop a well-rounded skill set, one must consider whether the lack of standardized learning competencies and the variance in backgrounds between different coaches builds strong coaches or simply a hodge podge of different philosophies. Further, a lack of standardized learning brings to question whether coaches receive adequate training in regard to key aspects of professionalism as a coach (e.g., ethics training, developmental psychology, first aid, etc.).

The lack of a standardized career hierarchy within college athletics (Franke, 2011; Glenn, 2014), particularly as it relates to the professional socialization through the apprenticeship role, may influence how coaches learn how to personally develop as coaches and to study their craft through career-long learning. Along the journey to reach a leadership position in strength and conditioning, participants in this study varied greatly in the path they took through the early parts of their careers. While half the participants followed a logical progression involving time spent in a part-time employment experience (i.e., internship, graduate assistantship), a low level assistantship, a more advanced associate position, and then finally a director or other leadership role, the remaining half experienced an accelerated jump from an entry to leadership position or entered directly into leadership positions.

As some coaches progressed rapidly from assistant to head strength and conditioning coach or director status, and had varying degrees of time spend under mentor coaches, learning styles and directions may have been influenced. Such variance in career progression, much like the differences reported between pre-professional backgrounds of coaches (e.g., early proximity to sport and training, athletic background, academic background), may merit additional 
scholarship aimed at exploring how coaches from different backgrounds explore learning through their careers.

Key findings in this project illustrate the learning tendencies in the form of CE for eight head strength and conditioning coaches in NCAA-DI football. The purpose of this section is threefold. First, how the current results support or oppose existing literature is explored. Next is an evaluation of the different participant' experiences and values with regard to CE as viewed through the lens of the theoretical framework. Lastly is a discussion of potential limiting factors and future directions for the study of how senior level strength and conditioning coaches learn through involvement with CE.

\section{What CE Experiences do Head College Football Strength and Conditioning Coaches Use Throughout Their Careers?}

Participants were actively engaged in a variety of CE learning experiences throughout their careers. This parallels recommendations in the existing literature that show that professionals should be active in CE throughout their entire career (Armour et al., 2009; Garet et al., 2001) and through a variety of different learning mediums (Lyle, 2002). More specifically, existing literature has noted that short or singular bouts of CE are often only surface level and may not be as impactful on professional learning (Armour et al., 2009). Further, long-term involvement in CE may be more impactful than shorter engagements as content can be explored much deeper and new knowledge can build upon past learning experiences of similar nature (Heibert et al., 1999). In the competitive industry of college athletics, where job security can be gauged upon successful professional practice, career-long engagement in $\mathrm{CE}$ may provide a 
competitive edge over other coaches in the field and continue to push coaches toward the development of coaching expertise.

As noted in existing literature (Anderson, 1982; Ericsson, 1993; Fitts \& Posner, 1967; Schempp et al., 2006), the persistent involvement in CE pushes professionals through different levels of expertise (novice, proficient, expert) and in this case, can assist in their overall effectiveness as a coach. Further, by remaining active throughout their career, Ericsson (2003) showed that coaches can "counteract automaticity" and a possible regression in practice with intentional efforts targeted at improving practice. Even as one coach in the study noted that he often "gravitated back to the old stuff," he actively used CE in order to remain current in his practice and to sharpen his skills as a coach and leader. Another coach echoed this by stating that "there's not any excuse to get stagnant by moaning and stop increasing in value." Through involvement in $\mathrm{CE}$, coaches have the ability to learn new concepts, challenge preexisting philosophies, and remain current in the field. Such deliberate attempts at moving forward with professional practice may actually be more important than the content that is learned, and as noted by Ericsson (2003), these ongoing efforts are what push professionals toward the development of expertise.

Also similar to the existing literature, in this study, participants showed active involvement in different forms of learning ranging from formal to informal and with varying degrees of planning involved prior to the CE experience. Further, coaches detailed their CE experiences in regard to the content they learned or their experience in which they were involved (Garet et al., 2001). A better understanding of what content and experiences coaches utilize may be impactful for future planning of CE experiences for coaches, especially in regarding to looking at the relationship between content knowledge, a core feature, and how such content was 
delivered within the infrastructure of the learning experience, a structural feature (Garet et al., 2001).

It is also evident that the majority of the participants' experiences can be designated as reform style CE, or activities such as interactions in study groups and direct day to day coaching (Birman et al., 2000; Garet et al., 2001). These experiences include learning through informal social connections, self-study, workplace experience, and non-traditional learning at conferences. Although not necessarily better than traditional forms of CE that typically exist as lectures to large audiences or online videos delivered to the masses, reform style CE often is more situated in the actual workplace and can be more authentic than content delivered in the sterile confines of a conference or a classroom (Birman et al., 2000; Garet et al., 2001).

\section{Social connections.}

Coaches noted learning relationships with other professionals who they considered more advanced than them. This is similar to social learning theories that note that individuals learn from other individuals with more advanced skills or training (Vygotsky, 1978). Such learning relationships may exist through peer to peer communication, proximity to and interactions with head sport coaches that strength and conditioning coaches directly support, and among experiences with athletes. Coaches also noted trust as a major factor in seeking social learning opportunities. This trust that exists amongst peers in the field may play a vital role in social learning because without it, coaches may be hesitant as to the depth of content they share with other professionals, especially those coaches outside their specific team (Wright, Trudel, \& Culver, 2007) 


\section{Self-study.}

Much like the learning opportunities that exist in the form of social interactions, involvement with self-study varied greatly between participants. The self-study experiences that coaches discussed exist as informal and planned CE (Fraser et al., 2007; McKinney et al., 2005). Personal research on opponent practices, reading, and the utilization of different multimedia platforms were reported as the most common form of self-study. Existing literature has shown that coaching at the collegiate level is both stressful (Kelley, 1994) and demanding in regard to the multi-directional responsibilities that often exist for coaches (Mazerolle \& Pitney, 2011). Responses echoed this, and as one coach stated, "collegiate strength and conditioning is a world of busy." Because of this, self-study may be an attractive option for professionals as such learning allows coaches to learn on their own time when it best fits their schedule.

An interesting consideration pertaining to self-study is the lack of participation in online quizzes sponsored by the professional organizations and that play a large role in the management of professional certification. These quizzes are typically formal learning experiences that are usually planned, but can have incidental characteristics if used in an emergency to acquire last minute credits to satisfy CE (CEU) units. (Fraser et al., 2007; McKinney et al., 2005). It is attention-grabbing why the quiz format of guided learning is not used more as a means of selfstudy. Moving forward, it could be beneficial to explore deeper into these opportunities and how they are perceived by the learner to potentially revamp the content or structure to better suit the needs of the professional. 


\section{Experience as CE learning.}

Paralleling past literature on the impact that reflective practice may have on coaching effectiveness (Gilbert \& Trudel, 2001; Gilbert \& Trudel, 2005) coaches noted past experiences at different points in their careers that they recognized as learning experiences. Many responses pertained to positive experiences that exist in the workplace, however, negative or challenging situations were also reported to be learning opportunities among coaches. Experience exists as a true informal, reform style (Birman et al., 2000; Garet et al., 2001) form of CE. Coaches reported being simply "thrown into the fire" and learning from "sink or swim" experiences and noted such experiences to be very impactful on their development as a coach. Experience was reported to be both planned and incidental in nature. Experience as learning may take place in situations where coaches test out different skills (planned) as well as workplace learning opportunities situated directly in their day to day operations (incidental).

One of the more comprehensive forms of experience as CE noted by coaches learning opportunities during professional internships. Existing literature categorizes these experiences as nonformal coach education (Cushion et al., 2003; Merriam et al., 2007), and as noted by Cushion and colleagues (2003), in such internship experiences, mentors are often active and play a major role in the development of their pupils. During such internship experiences, developing coaches have the ability to learn and test out skills in a controlled environment, where mistakes may be corrected by an elder coach. It is intriguing to consider the impact that a positive internship experience may have on a developing coach during the development of his or her initial skill set and in the development of a personal career learning philosophy. 


\section{Conference CE learning.}

Conferences provide opportunities for both planned and incidental learning via a mixture of formal and informal experiences. Coaches noted active participation in conferences, however, as Armour and colleagues (2009) show, traditional lecture style presentations at conferences often only speak to the surface of topics and may not be as impactful as learning experiences that exist in longer durations. Regardless of past scholarship in the area, however, it is important to note the perceived importance of learning through attending lectures that was noted by participants.

In addition to formal learning at conferences, coaches reported other learning opportunities including networking with other coaches, learning from vendors, and working to administer the entire conference. Further, conference attendance allows face to face interactions with colleagues that don't occur regularly due to constraints such as location and time. This informal "beer-learning" may be either planned or incidental (Fraser et al., 2007; McKinney et al., 2005), and provides an opportunity for likeminded professionals to discuss different concepts and ideas. Vickers (2007) discusses communities of practice at coaching clinics and how during most of these informal interactions, coaches often spend the majority of the time talking with other coaches of similar status and with colleagues they personally know.

The infrastructure of the conference, or collection of professionals, as noted by Garet and colleagues (2001), is a structural feature that may be impactful on cultivating learning amongst professionals. The different responses noted by participants makes it interesting to consider whether it is the planned learning that is associated with conference (i.e., lectures and events) that coaches learn from or simply the environment, learning situations, and close proximity to 
other successful coaches that promotes the most impactful infrastructure of learning for these coaches.

Another potentially overlooked opportunity for learning within the conference setting is the social interactions occurring within the vendor halls. As an interactive environment and natural meeting location within the conference setting, the vendor hall provides a unique opportunity for unplanned conversations and incidental learning experiences that is in line with the positive environment and means of delivery as important aspects of learning (Garet et al., 2001). Vendor halls may provide coaches a viable supplement to commonly accepted forms of learning at conferences.

\section{Graduate school experience.}

The only institutionalized, formal (Mallett et al., 2009; Trudel \& Gilbert, 2006) means of CE reported was graduate school education. Coaches indicated that the nature of college sports may be unfriendly to being involved in graduate education as the nomadic nature of the profession makes it less likely that coaches will complete a multi-year graduate plan of study. Further, as strength and conditioning coaches exist as supporting figures, often to their head football coach, any staff change up the chain may trigger a cascade of events for members of the strength staff. This may be a reason the majority of responses from the participants were noted to be informal in nature as opposed to long-term structured experiences.

At the graduate school level, strength and conditioning coaches are often prepared through specialized programs in the field. It is possible that the current structure and content covered in graduate school is not applicable or authentic enough to foster learning amongst strength and conditioning coaches. Jones (2000) showed that coaching education often lacks the 
authenticity needed to transfer to actual coaching experiences. Macdonald and Tinning (1995) continue by noting that coach education must not aim to produce practitioners that can simply regurgitate facts and provide services, but rather active thinkers with professional skills, a knowledge of the field, and a strong ethical orientation.

Sadly, academic programs geared toward coaching education appear to focus mostly on content knowledge that lacks context, leaving students underprepared in regard to their inter- and intra-personal development and left to seek information in those areas from other disciplines (Jones, 2000). This is unfortunate because universities are in position to play a major role in CE amongst professionals (Cervero, 2000). According to Cervero's (2000) second and third trend, universities and parent organizations play a major and influential role in CE experiences that are provided for the professionals in a specific field. However, in conflict with Cervero's work, coaches in this study indicated that most learning took place on an individual or informal basis outside of formal education or professional organizational level.

\section{What Values do Head College Football Strength and Conditioning Coaches Have for CE?}

Paralleling existing literature, coaches indicated the desire to be involved in CE throughout their careers in order to move toward expertise and also noted specific competencies that they felt were requisite skills of high level coaches. Existing literature shows that experts in different fields display advanced qualities that separate them from their less experienced peers (DeMarco \& McCullick, 1997; Schempp et al., 2006). These qualities may include an extensive knowledge base within their field of practice, automatic behavior, and advanced decision making capabilities. Further, these individuals often spend more time than their less experienced peers in planning and organization activities (DeMarco \& McCullick, 1997; Schempp et al., 2006). Côté 
and Gilbert (2009) show that expert coaches tend to have the ability to consistently develop athletes at different levels, hold strong foundational knowledge in regard to many different areas of coaching, and have the ability to successfully practice their craft in various coaching situations.

The present study identified a variety of skills and knowledge that coaches felt were the responsibility of coaches to learn. Much like the areas of coaching expertise noted by Côté and Gilbert (2009), many of the skills that coaches spoke about included technical and tactical aspects of coaching, however they also noted that coaches must have the ability to teach different types of learners and the ability to discriminate good from bad information throughout their personal learning experiences. In regard to learning quality content, one coach went as far as to say that coaches must "lean their ladder on the right wall." The use of quality content may increase the ability coaches have to synthesize what they learn and then add it to their coaching toolbox. Ultimately, participants noted that a growth mindset allowed coaches to be open to learning a variety of skills and knowledge throughout their careers.

Coaches were seen to be active within professional organizations and it was apparent that participants felt as though CE was important in the development of knowledge and skills as well as for their progression in the field. This parallels existing literature (Gould, Giannini, Krane, \& Hodge, 1990) that shows the impact that quality coaching organizations that sponsor positive learning experiences can have on coach development. Participation of coaches in this study ranged from simple certified membership to full leadership status on decision making committees. Additionally, all coaches felt as though it was a professional responsibility to be active in the professional organizations and more than half of the coaches pushed their staff members toward active membership in a variety of organizations. 
Coaches indicated involvement in both of the main professional organizations that exist in collegiate strength and conditioning. Each of these organizations provide unique experiences for coaches and exists with a specific purpose. The National Strength and Conditioning Association has an inclusive membership model and is focused on research and evidence based practice while the Collegiate Strength and Conditioning Coaches Association (CSCCa) has a more exclusive membership model and focuses more on coach development as opposed to research. It is interesting to consider whether the coaches were drawn to an organization that affirmed their initial beliefs or were there specific reasons they made such choice (Sherman, 2017). Even though coaches reported a main organization that they were most active in, nearly all participants mentioned holding dual certified membership with both organizations. This dual membership may speak to the importance that these coaches place on being active with different organizations in the field.

Another primary area of emphasis was the importance that coaches placed on staff development. Coaches with many years of experience often possess skills that their less experienced colleagues have not yet been able to develop (DeMarco \& McCullick, 1997; Schempp et al., 2006). Several participants in the current study reported the operation of a nonformal staff development program under their watch which could provide positive mentorship guidance and learning experiences in the form of CE. Lortie (1975) introduced the concept of the apprenticeship of observation that exists during the development of teachers. During this period, that exists long before teacher pre-professional education, when teachers are still students, teachers indirectly observe the habits and practices of their teachers and when they finally become employed as a teacher themselves, often exhibit some of the same characteristics of the teachers they inadvertently learned from during their younger years. During nonformal 
staff development experiences, internship opportunities, or during time spent as athletes themselves, it is possible that developing coaches can learn much like teachers in an apprenticeship of observation experience.

\section{How Can CE be Improved to Assist Individual Strength and Conditioning Coaches and the Entire Profession?}

Despite the importance of CE, potential inhibiting factors that that prevent strength and conditioning coaches from realizing the full potential of their desire to learn exist. Ericsson (1993) showed that even though a professional may engage in learning through their career, external limitations such as a lack of opportunity or limited infrastructure for education may shunt growth that could have been realized. Further, internal inhibitors such as a lack of motivation or a limited desire to continue to learn may also prevent professionals from learning. Additionally, Gladwell (2008) discussed other factors that may limit learning that included the lack of ability or talent, the absence of a support system that encourages and sustains involvement in an activity, and geographical seclusion that may limit the amount of opportunities a person may have to be engaged in an activity.

Contrary to existing literature (Ericsson, 1993; Gladwell, 2008), no coaches in the study mentioned a lack of internal motivation to learn, however they did note structural issues within organizations and in the day to day practice of professionals that could potentially be handicapping learning for coaches. There may, however, exist potential inhibiting factors that impact the effectiveness of CE experiences. Coaches noted a lack of unification that exists among both professionals and organizations in the field, the lack of time that exists for CE experiences, and the constraints the NCAA places on staffs with sanctions related to staff size. 
Coaches noted that to improve learning experiences, there should be a movement toward the active unification of the field on a personal and organizational level. Similar to the structure and practice set forth by the field of Athletic Training during its development (Delforge \& Behnke, 1999), efforts to establish a common bond, set of practices, and core competencies for learning may strengthen both CE opportunities that are provided for coaches as well as well as the entire field. There exists two independent, self-sustaining professional organizations within strength and conditioning in the United States and currently, it appears as if they do not collaborate. Further, there does not seem to be plans to unify or share joint practice in the near future.

Coaches discussed the need for unification of the field at the individual coach level and brought to light the existence of resistance to sharing information between colleagues. This parallels existing literature on communities of practice in athletic coaching (Trudel \& Gilbert, 2004) that cites the competitive nature of sport as a potential barrier to professional learning based on resistance to sharing strategies and other secrets with opponents in a competitive profession. Due to the "competition factor" and high-stakes nature of elite college sport, nonsanctioned sharing of information may be viewed as treason within the coaching community (Wright et al., 2007, p. 136).

As the field of strength and conditioning continues to mature and grow with more evidence based practice, it could be beneficial to continue to cultivate collaborative networks in the form of communities of practice (Lave \& Wenger, 1991; Wenger, 2000) where coaches feel safe disclosing practices and other knowledge. It would be interesting to also look at ways in which coaches could work to share and collaborate the science aspect of coaching that is present in the profession while keeping the art or individual flavor of their actual coaching private. 
Key areas that may enhance coaching effectiveness and the overall professionalism of the field may include the study and development of skills pertaining to professional (i.e., technical, tactical, physical), interpersonal (i.e., social contexts, relationships, coaching methodology), and intrapersonal (i.e., coaching philosophy and lifelong learning) coaching knowledge (International Council for Coaching Excellence, 2012). In order to continue to progress professional knowledge, coaches should be encouraged to explore a variety of different types of learning opportunities, such as independent self-guided learning, peer-to-peer communication, and longitudinal practical experiences throughout their career. Undermining this important growth mindset is the fact that opportunities that supply positive learning experiences may not be recognized as sanctioned CE by the key professional associations.

It is possible that as the strength and conditioning profession works to develop holistic, professional skills like the athletic training sector has done (Delforge \& Behnke, 1999), there may be even more room for growth and stability within the field. Potentially the best way to encourage learning amongst coaches is to improve the overall professional behavior of the entire field, and as discussed by participants, this is a major area in need of improvement within collegiate strength and conditioning.

\section{The impact of NCAA legislation on strength and conditioning coaching.}

Another potentially limiting factor on the career-long CE of coaches involves the rules governing strength and conditioning coaching staffs in NCAA-DI football. Currently, the NCAA places mandates on the number of strength and conditioning coaches a NCAA-DI FBS program may employ. This produces major limitations for future generations of coaches that are actively seeking positions that simply do not exist. As governed by the NCAA, five strength and 
conditioning coaching positions exist for each of the 128 NCAA-DI FBS (640 total positions) universities that compete in football. Additionally, not all universities have the ability to fund their entire five position quota and exist with less than five football strength and conditioning coaches.

Jones (2000) shows that formal coach learning often does not fully prepare coaches for actual practice. As coaching opportunities are often scarce and difficult to obtain, this may further exacerbate the situation for developing coaches who are looking for learning experiences and a start in the field. More active collaboration between the NCAA, the professional organizations that support coaches in the field, and the individual strength and conditioning coaches should take place. Further, emphasis should be placed on the development of enhanced standards and parameters for practice that level the playing field between different schools and also provide better learning experiences for future generations of coaches.

\section{Individual Backgrounds and Its Impact on CE.}

Participant backgrounds leading up to initial employment as coaches were different between participants. Paralleling existing literature on strength and conditioning coaches (Brooks et al., 2000; Kontor, 1989; Massey et al., 2004), participants in the study exhibited a variety of preprofessional backgrounds regarding sport and education. Such differentiated backgrounds provided unique and individualized developmental paths for coaches on their route to the development of expertise. This may prove influential on the learning trajectories of coaches and make CE vital for the delivery of key professional training (i.e., ethics training, developmental psychology, first aid, etc.). 
Scholarship in physical education teacher education literature has explored the learning dispositions and impact of background on the development and implementation of skills and knowledge learned through formal training. Lawson (1983) explored the occupational socialization process of physical education teachers and the path that teachers navigate as they move from students themselves, through university studies, and then finally to fully vetted teacher status. While traditional theories of teacher socialization note that these processes originate with formal teacher education (Burlingame, 1972; Earls, 1981), Lawson (1983) argued that this process begins with the development of a subjective warrant or a set of beliefs and values about a professional career and occurs when they are students themselves, long before they enter into formal teacher training.

Similar to the development of the subjective warrant and the research on the development of teachers (Lawson, 1983), the active involvement in sport, education, and the proximity to educators noted by coaches in the study may prove to be a factor in their initial interest in the field and continued participation in learning and developing within strength and conditioning. The opportunities to be around training and positive role models were noted to be important as participants were able to observe and experience developmentally appropriate hands on experience early on in their lives. Such experiences provided opportunities for participants to be around mentors and training experiences long before they were coaches and built the foundation for future learning experiences they experienced later in their careers.

The variance in educational backgrounds among participants in the study parallels existing literature (Brooks et al., 2000; Kontor, 1989; Massey et al., 2004). From participant responses, it was interesting to see the impact that different forms of education had on their careers; both in regard to their active involvement as well as their proximity to other educators. 
For example, coaches with degrees in the field of sport or exercise science may possess foundational knowledge of training and choose to pursue extended learning experiences outside of basic training theory, while coaches that possess degrees in other fields may explore foundational tenets of strength and conditioning as their primary means of CE. Further, the proximity to education and teachers may have been influential on the way the participants viewed learning through their career and their overall involvement in CE. The lack of consistently between backgrounds may provide evidence that CE throughout coaches' careers may be integral in order to ensure career-long development.

Coaches also discussed battling through challenges while they were athletes. Similar to existing literature (Lawson, 1983) that shows that teachers often revert back to their subjective warrant when faced with challenges, this may also impact coaches as well. As coaches are often viewed as teachers (Jones, 2006), it is intriguing to consider that this may be manifested in the drive coaches have toward learning and engaging in CE. As coaches face challenges in their professional career, they may reflect back on how they pushed through challenges as an athlete or how they observed a coach work to solve a problem.

\section{Limitations of Research}

From the findings of this study, it was shown that not all $\mathrm{CE}$ takes place under the guidance of the professional organizations in the field or within a university setting. Learning can take place at any time and often times is situated in the day-to-day experiences of professionals (Lave \& Wenger, 1991; Wenger, 2000). With this, it is possible that participants in this study did not fully recognize the informal, situated learning experiences that they were exposed to for CE nor did they report it during the interview process. While not traditionally 
reported for $\mathrm{CE}$ credit for recertification, it should be recognized that learning is ongoing and takes place in many different settings.

As participants in the study were asked to recall previous events, limitations associated with retrospective recall must be considered. Further, response bias (Dodd-McCue \& Tartaglia, 2010; Phillips \& Clancy, 1972), or the inaccurate reporting of what occurred due to potential judgment by others may also factor into responses. Further, as the study looks to examine the CE pursuits of NCAA-DI FBS head football strength and conditioning coaches, it is possible that they did not fully disclose their practices in order to keep a competitive advantage from their opponents. It was noted in the findings that the sharing of information amongst all coaches in NCAA-DI football is often discouraged to prevent losing a competitive edge. With this, it is possible that participants did not fully disclose complete and truthful pursuits, attitudes, and values toward involvement in $\mathrm{CE}$ in order to keep such information from their opponents.

It is also important to note the difficulties that existed during the search for participants and how this may have influenced the responses that were obtained during the interviews. During the recruitment phase, there was limited response back from potential participants as well as the existence of experimental mortality (Jurs \& Glass, 2015) as two original participants dropped out of the study because of career moves and no longer met inclusion criteria. Turnover in college coaching is often high (Branch, 2011; Holmes, 2010), and in fact, at the completion of this study, only two of the eight participants were still employed in the same position that they held at the time of the interview. Because of the difficulties securing participants, the search was expanded to multiple athletic conferences in NCAA-DI and convenience sampling (Patton, 2002) was used to identify specific coaches that would meet the parameters of the study and be willing to participate. 
With this, it is important to consider the impact that the intentional targeting of specific coaches had on the responses provided by the participants. Additionally, as some coaches were more willing than others to participate in the study, there may exist differences in attitudes and values toward career-long learning. In light of the sample, the coaches that were willing to participate may have been more interested in CE and this interest may have influenced their responses. Further, as noted in the responses, career-long learning in the form of CE was noted to be a professional responsibility, and those coaches that willingly participated may have been more professionally active in CE as compared to the coaches that did not wish to be in the study. If, in fact this was the case, it would be interesting to know the different forms of CE that are used by coaches that were not willing or were unable to participate in the study.

A final potential limitation to consider is preexisting primary investigator bias. While efforts were made to be aware of and reduce bias, at the time of the study, the primary investigator was a NCAA-DI strength and conditioning coach, in the same field as the participants who were part of the study. Because of this, there is always the potential that the researcher impacted data analysis or interpretation of findings. This could potentially influence the collection of information, the interpretation of data, and the overall conclusions of the study.

\section{Conclusion and Future Research}

Strength and conditioning coaches in NCAA-DI football come from a wide variety of backgrounds and have many unique skills (Brooks et al., 2000; Kontor, 1989; Massey et al., 2004). They also engage in many different forms of CE that can be identified as formal coach education (Abraham \& Collins, 1998; Cushion et al., 2003; Trudel \& Gilbert, 2006), informal coach education (Cushion et al., 2003; Rynne, 2010), and non-formal coach education (Cushion 
et al., 2003; Merriam et al., 2007). While the NCAA recommends that all DI strength and conditioning coaches maintain certification through a nationally accredited organization (e.g. NSCA - CSCS, CSCCa - SCCC) there is no standardized path toward expertise in the field. Further, as Jones (2000) notes, the current structure of coaching education in the United States is often insignificant in the development of coaches. Despite the lack of a professional standard for learning as a coach and the marginal results that current coaching education may yield, CE can serve as a valuable tool for both personal growth, and progression of the entire field of collegiate strength and conditioning.

The current study utilized qualitative content analysis methods to examine data collected via online questionnaire and through semi-structured interviews. Further research should extend the present study into the analysis of CE learning preferences of strength and conditioning coaches at various stages of their careers. This could yield important information that could assist developing coaches during their journey toward the development of expertise. Further, examining the backgrounds of coaches (e.g., academic, athletic, social) could also provide valuable information for institutions that provide $\mathrm{CE}$ experiences. As more is known about the clientele that is learning from the CE, better experiences can be tailored to meet their needs.

Existing literature notes that experts possess skills that allow them to outperform their less talented peers on a consistent basis (DeMarco \& McCullick, 1997; Schempp et al., 2006). Projects in the future should explore how CE throughout a coach's career influences their skill repertoire and behavior and how that change impacts their performance as a coach in regard to teaching and feedback, decision making, and planning. As more is known about the most effective means of learning through $\mathrm{CE}$, better learning experiences could be developed that meet the needs of different strength and conditioning coaches. 
A study of social networks that exist in the field could also aid in the analysis of how coaches move toward a level of expertise throughout their careers. From past literature and results of this project, it has been shown that learning is often situated in practice and among a group of peers or colleagues (Lave \& Wenger, 1991; Wenger, 2000). The organizational structure of such groups or networks could be evaluated in order to uncover the practices and areas for improvement that would benefit the entire profession and ultimately athlete development. 


\section{References}

Abernathy, B. (2008). Developing expertise in sport: How research can inform practice. In D. Farrow, J. Baker, \& C. MacMahon (Eds.), Developing sport expertise: Researchers and coaches put theory into practice (pp. 1-14). New York, NY: Routledge.

Abraham, A., \& Collins, D. (1998). Examining and extending research in coach development. Quest, 50(1), 59-79.

American Sport Education Program. (2011). Retrieved from http://www.asep.com/about.cfm

Anderson, J. R. (1982). Acquisition of cognitive skill. Psychological Review, 89(4), 369-406.

Armstrong, K.J., \& Weidner, T.G. (2010). Formal and informal continuing education activities and athletic training professional practice. Journal of Athletic Training, 45(3), 279-286.

Armour, K., Makopoulou, K., \& Chambers, F. (2009). The learning teacher in physical education. In L. D. Housner, M. W. Metzler, P. G. Schempp, \& T. J. Templin (Eds.), Historic traditions and future directions of research on teaching and teacher education in physical education (pp. 213-220). Morgantown, WV: Fitness Information Technology.

Armour, K.M., \& Yelling, M.R. (2004). Continuing professional development for experience physical education teachers: Towards effective provision. Sport, Education, and Society, 9(1), 95-114.

Austin, Z., Marinia, A., Glover, N.M., \& Croteaue, D. (2005). Continuous professional development: A qualitative study of pharmacists' attitudes, behaviors, and preferences in Ontario, Canada. American Journal of Pharmaceutical Education, 69(1), 25-33. 
Barrosso, J. (1997). Social support and long-term survivors of AIDS. Western Journal of Nursing Research, 19(5), 554-582.

Birman, B.F., Desimone, L., Porter, A.C., \& Garet, M.S. (2000). Designing continuing education that works. Educational Leadership, 57(8), 28-33.

Bompa, T., \& Haff, G. G. (2009). Periodization: Theory and methodology of training. Champaign, IL: Human Kinetics.

Borko, H. (2004). Continuing education and teacher learning: Mapping the terrain. Educational Researcher, 33(8), 3-15.

Branch, T. (2011). The shame of college sports. The Atlantic Magazine, 308(3), 80-110. Retrieved from http://www.workplacebullying.org/multi/pdf/branch.pdf.

Brooks, D.D., Ziatz, D., Johnson, B., \& Hollander, D. (2000). Leadership behavior and job responsibilities of NCAA Division 1A strength and conditioning coaches. Journal of Strength and Conditioning Research, 14(4), 483-492.

Burlingame, M. (1972). Socialization constructs and the teaching of teachers. Quest, 16, 40-56.

Carr, W.D., Ploeger, R.L., \& Drummond, J. (2007). Learning over time: A literature review and case study. Athletic Therapy Today, 12(5), 20-25.

Cervero, R. (2000). Trends and issues in continuing professional education. New Directions for Adult and Continuing Education, 86, 3-12.

Coaching Association of Canada. (2011). About CAC: Who we are. Retrieved from http://www.coach.ca/who-we-are-s13411 
Coffey, A., \& Atkinson, P. (1996). Making sense of qualitative data. Complementary research strategies. London: Sage Publications Inc.

Collegiate Strength and Conditioning Coaches Association. (2011a). About. Retrieved from http://www.cscca.org/about

Collegiate Strength and Conditioning Coaches Association. (2011b). Continuing education program. Retrieved from http://www.cscca.org/education/ceu

Côté, J., \& Gilbert, W. (2009). An integrative definition of coaching effectiveness and expertise. International Journal of Sports Science \& Coaching, 4(3), 307-323.

Craft, A. (1996). Nourishing educator creativity: An holistic approach to continuing professional development. British Journal of In-service Education, 22(3), 309-323.

Creswell, J. W. (2009). Research Design: Qualitative, quantitative, and mixed methods approaches. Los Angeles: Sage Publications.

Creswell, J.W., \& Creswell, J.W. (2013). Qualitative inquiry \& research design: Choosing among five approaches. Los Angeles: Sage Publications.

Culver, D., \& Trudel, P. (2008). Clarifying the concept of communities of practice in sport. International Journal of Sports Science \& Coaching, 3(1), 1-10.

Cushion, C. J., Armour, K. M., \& Jones, R. L. (2003). Coach education and continuing professional development: Experience and learning to coach. Quest, 55, 215-230.

Dawes, R.M. (1994). House of cards: Psychology and psychotherapy based on myth. New York: The Free Press. 
Delforge, G.D. \& Behnke, R.S. (1999). The history and evolution of athletic training education in the United States. Journal of Athletic Training, 34(1), 53-61.

DeMarco Jr. G.M. \& McCullick, B.A. (1997). Developing expertise in coaching: Learning from the legends. Journal of Physical Education, Recreation \& Dance, 68(3), 37-41.

Dodd-McCue, D., \& Tartaglia, A. (2010). Self-report response bias: Learning how to live with its diagnosis in chaplaincy research. e-Journal of the Association of Professional Chaplains, 26(1), 2-8.

Downey, A.B. (2012). Think Bayes: Bayesian statistics made simple. Needham, MA: Green Tea Press.

Durrell, D.L., Pujol, T.J., \& Barnes, J.T. (2003). A survey of the scientific data and training methods utilized by collegiate strength and conditioning coaches. Journal of Strength and Conditioning Research, 17(2), 368-373.

Earls, N.F. (1981). Distinctive teachers' personal qualities, perceptions of teacher education and the realities of teaching. Journal of Teaching in Physical Education, 1, 59-70.

Elstein, A.S., Shulman, I.S., \& Sprafka, S.A. (1978). Medical problem solving: An analysis of clinical reasoning. Cambridge, MA: Harvard University Press.

Ericsson, K.A. (1993). The role of deliberate practice in the acquisition of expert performance. Psychological Review, 100(3), 363-406.

Ericsson, K. A. (2003). Development of elite performance and deliberate practice: An update from the perspective of the expert performance approach. In J. L. Starkes, \& K. A. 
Ericsson (Eds.), Expert performance in sports: Advances in research on sport expertise (pp. 49-83). Champaign, IL: Human Kinetics.

Ericsson, K.A. (2007). An expert-performance perspective of research on medical expertise: The study of clinical performance. Medical Education, 41, 1124-30.

Ericsson, K.A. (2008a). The making of an expert. ASCA Newsletter, 11, 18-26.

Ericsson, K.A. (2008b). Deliberate practice and acquisition of expert performance: A general overview. Academic Emergency Medicine. 15(11), 989.

Fitts, P.M. \& Posner, M.I. (1967). Human Performance. Belmont, CA: Brooks/Cole.

Fekete, M. (1999). The role of continuing education in the NSCA. Strength and Conditioning Journal, 21(4), 67-70.

Franke, W. (2011). Careers in fitness instruction, personal training, and fitness management. In S. Hoffman (Ed.), Careers in sport, fitness, and exercise: The authoritative guide for landing the job of your dreams (pp. 39-42). Champaign: Human Kinetics.

Fraser, C., Kennedy, A., Reid, L., \& McKinney, S. (2007). Teachers' continuing professional development: Contested concepts, understandings and models. Journal of In-service Education, 33(2), 153-169.

Gardiner, A. \& Mensch, J.M. (2004). Promoting continuing education in athletic training. Athletic Therapy Today, 9(4), 30-31. 
Garet, M. S., Porter, A. C., Desimone, L., Birman, B. F., \& Yoon, K. S. (2001). What makes continuing education effective? Results from a national sample of teachers. American Educational Research Journal, 38(4), 915-945.

Gabriel, S. (2008). From the laboratory to the weight room: Applying research to practice. Strength and Conditioning Journal, 30(4), 70-71.

Gilbert, W.D. \& Trudel, P. (2001). Learning to coach through experience: Reflection in Model Youth Sport Coaches. Journal of Teaching in Physical Education, 21, 16-34.

Gilbert, W.D. \& Trudel, P. (2005). Learning to coach through experience: Conditions that influence reflection. Physical Educator, 62, 32-43.

Gilbert, W., Côté, J., \& Mallett, C. (2006). Developmental paths and activities of successful sport coaches. International Journal of Sports Science \& Coaching, 1(1), 69-76.

Gilbert, W.D. \& Baldis, M.W. (2014). Becoming an effective strength and conditioning coach. Strength and Conditioning Journal, 36(1), 28-34.

Gladwell, M. (2008). The Matthew Effect. In Outliers: The story of success. New York: Little, Brown, and Co.

Glaser, B. \& Strauss, A. (1967). The discovery of grounded theory: Strategies for qualitative research. New York: Aldine Publishing Company.

Glaser, B.G. (2000). The future of grounded theory. Grounded Theory Review. 1(1), 8. 
Glenn, W. (2014). The path to the athletic director's office. Sports Business Journal, 6, Retrieved from http://www.sportsbusinessdaily.com/Journal/Issues/2014/06/09/InDepth/Wong-column.aspx.

Gould, D., Giannini, J., Krane, V., \& Hodge, K. (1990). Educational needs of elite U.S. National team, Pan American, and Olympic coaches. Journal of Teaching in Physical Education, 9(4), 332-344.

Grant, M.A. \& Dorgo, S. (2014). Developing expertise in strength and conditioning coaching. Strength and Conditioning Journal, 36(1), 9-15.

Grant, M.A., Dorgo, S., \& Griffin, M. (2014). Professional development in strength and conditioning through informal mentorship: A practice pedagogical guide for practitioners. Strength and Conditioning Journal, 36(1), 63-69.

Graneheim, U.H., \& Lundman, B. (2004). Qualitative content analysis in nursing research: Concepts, procedures, and methods to achieve trustworthiness. Nurse Education Today, $24,105-112$.

Guskey, T.R. (2002). Continuing education and teacher change. Teachers and Teaching: Theory and Practice, 8(3/4), 381-391.

Hiebert, J., Carpenter, T. P., Fennema, E., Fusen, K., Human, P., Murray, H., Olivier, A., \& Wearne, D. (1999). Problem solving as a basis for reform in curriculum and instruction: The case of mathematics. Educational Researcher, 25(4), 12-21.

Holmes, P. (2010). Win or go home: Why college football coaches get fired. Journal of Sports Economics, 12(2), 157-178. 
Horton, S., \& Deakin, J.M. (2008). Expert coaches in action. In D. Farrow, J. Baker, \& C. MacMahon (Eds.), Developing sport expertise: Researchers and coaches put theory into practice (pp. 75-88). New York, NY: Routledge.

International Council for Coaching Excellence. (2012). International Sport Coaching Framework. Champaign: Human Kinetics.

Issurin, V.B. (2008). Block periodization versus traditional training theory: A review. The Journal of Sports Medicine and Physical Fitness, 48(1), 65-75.

Issurin, V.B. (2010). New horizons for the methodology and physiology of training periodization. Sports Medicine, 40(3), 189-206.

Jeffreys, I. (2014). The five minds of the modern strength and conditioning coach: The challenge for professional development. Strength and Conditioning Journal, 36(1), 2-8.

Jones, R. L. (2000). Toward a sociology of coaching. In R. J. Jones, \& K. M. Armour (Eds.), The sociology of sport: Theory and practice (pp. 33-43). London: Addison Wesley.

Jones, R.L. (2006). How can educational concepts inform sports coaching? In R. Jones (Ed.), The sports coach as educator (pp. 3-13). New York: Routledge.

Jurs, S.G., \& Glass, G.V. (2015). The effect of experimental mortality on the internal and external validity of the randomized comparative experiment. The Journal of Experimental Education, 40, 62-66.

Kelley, B.C. (1994). A model of stress and burnout in collegiate coaches: Effects of gender and time of season. Research Quarterly for Exercise and Sport, 65(1), 48-58. 
Klein, D., Allan, M., Manca, D., Sargeant, J., \& Barnett, C. (2009). Who is driving continuing medical education for family medicine? Journal of Continuing Education in the Health Professions, 29(1), 63-67.

Kontor, K. (1989). Defining a profession. NSCA Journal, 11(4), 75.

Kraemer, W.J. (1990). Education and learning. National Strength and Conditioning Association Journal, 12(6), 72-73.

Lawson, H.A. (1983). Toward a model of teacher socialization in physical education: The subjective warrant, recruitment, and teacher education. Journal of Teaching in Physical Education, 2(3), 3-16.

Layden, T. (1998). Power play. Sports Illustrated, 89(4), 61-65.

Lave, J., \& Wenger, E. (1991). Situated learning: Legitimate peripheral participation. Cambridge: Cambridge University Press.

Lortie, D. (1975). The schoolteacher: A sociological study. London: University of Chicago Press.

Lyle, J. (2002). Coach education and coaching practice. In J. Lyle (Ed.), Sports coaching concepts: A framework for coaches' behavior (pp. 274-290). London: Routledge.

Lyoka, P.A. \& Xoxo, T. (2011). Changing landscape of coaching expertise and need to strategize research: A review. African Journal for Physical, Health Education, Recreation and Dance, 20(3:1), 939-954. 
Macdonald, D. \& Tinning, R. (1995). Physical education teacher education and the trend to proletarianization: A case study. Journal of Teaching in Physical Education, 15, 98-118.

Mallett, C. J., Trudel, P., Lyle, J., \& Rynne, S. B. (2009). Formal vs. informal coach education. International Journal of Sports Science \& Coaching, 4(3), 325-334.

Manners, J., \& Scifers, J. (2005). Continuing-education ethics and professionalism. Athletic Therapy Today, 10(5), 58-59.

Mannie, K. (2007). Career path for the strength/conditioning professional. Coach and Athletic Director, 76(6), 8-9.

Martinez, D.M. (2004). Study of the determining factors for the NCAA Division I head strength and conditioning coach. Journal of Strength and Conditioning Research, 18(1), 5-18.

Mason, M. (2010). Sample size and saturation in PhD studies using qualitative interviews. Forum: Qualitative Social Research, 11(3), Art 8. Retrieved from: http://nbnresolving.de/urn:nbn:de:0114-fqs100387.

Massey, C.D., Vincent, J., \& Maneval, M. (2004). Job analysis of college Division I-A football strength and conditioning coaches. Journal of Strength and Conditioning Research, $18(1), 19-25$.

Mazerolle, S.M. \& Pitney, W.A. (2011). How to address finding a balanced lifestyle in the athletic setting: A perspective for the strength and conditioning coach. Strength and Conditioning Journal, 33(2), 43-45. 
McClellan, T., \& Stone, W.J. (1986). Research technique: A survey of football strength and conditioning programs for Division I NCAA universities. National Strength and Conditioning Journal, 8(2), 34-36.

McKinney, S., Carroll, M., Christie, D., Fraser, C., Kennedy, A., Reid, L., \& Wilson, A. (2005) AERS: Learners, learning, and teaching network project 2 - progress report, paper delivered at the Scottish Educational Research Association Annual Conference: Perth, Scotland, 24-26.

Merriam, S. B., Caffarella, R. S., \& Baumgartner, L. M. (2007). Learning in adulthood: A comprehensive guide. San Fransisco, CA: Jossey-Bass.

Miles, M.B. \& Huberman, A.M. (1994). Qualitative data analysis. Sage: Thousand Oaks, CA.

Moon, J.A. (2004). A handbook of reflective and experiential learning: Theory and practice. London: Routledge Falmer.

National Strength and Conditioning Association (2011a). Certification. Retrieved from http://www.nsca.com/Membership/WhyJoin/Benefits/certification.shtml

National Strength and Conditioning Association (2011b). Recertification. Retrieved from http://www.nsca-cc.org/ceus/recertification.html

Patton, M.Q. (1987). How to use qualitative methods in evaluation. Newbury Park: Sage.

Patton, M.Q. (2002). Qualitative research and evaluation methods. Newbury Park: Sage. 
Pauleen, D.J., Evaristo, R., Davison, R.M., Ang, S., Alanis, M., \& Klein, Stefan. (2006). Cultural bias in information systems research: Are you coming from the same place I am? Communications of AIS, 17(17), 2-36.

Peck, C., McCall, M., McLaren, B., \& Rotem, T. (2000). Continuing medical education and continuing education: International comparisons. British Medical Journal, 320, 432-435.

Phillips, D.L., \& Clancy, K.J. (1972). Some effects of "social desirability" in survey studies. American Journal of Sociology, 77(5), 921-940.

Pitney, W.A. (1998). Continuing education in athletic training: An alternative approach based on adult learning theory. Journal of Athletic Training, 33(1), 72-76.

Pullo, F.M. (1992). A profile of NCAA Division I strength and conditioning coaches. Journal of Applied Sport Science Research, 6(1), 55-62.

Rabin, M. \& Schrag, J.L. (1999). First impressions matter: A model of confirmatory bias. The Quarterly Journal of Economics, 114, 37-82.

Reade, I., Rodgers, W., \& Spriggs, K. (2008). New ideas for high performance coaches: A case study of knowledge transfer in sport science. International Journal of Sports Science \& Coaching, 3(3), 335-354.

Rynne, S.B., Mallett, C.J., \& Tinning, R. (2010). Workplace learning of high performance sports coaches. Sport, Education and Society, 15(3), 315-330.

Schempp, P.G., McCullick, B., \& Mason, I.S. (2006). The development of expert coaching. In R. Jones (Ed.), The sports coach as educator (pp. 145-161). New York: Routledge. 
Sherman, R. (2017). The perils of confirmation bias in coaching. Retrieved from http://team.fastmodelsports.com/2017/01/05/perils-confirmation-bias-coaching/

Tena, J.D., \& Forrest, D. (2007). Within-season dismissal of football coaches: Statistical analysis of causes and consequences. European Journal of Operational Research, 181, 362-373.

The National Strength and Conditioning Association Timeline (n.d.). Retrieved from National Strength and Conditioning Association Web site: http://www.nsca.com/1\%20Creation\%20of\%20NSCA.CEf

Torff, B., Sessions, D., \& Byrnes, K. (2005). Assessment of teachers' attitudes about continuing education. Educational and Psychological Measurement, 65(5), 820-830.

Trudel, P. \& Gilbert, W. (2004). Communities of practice as an approach to foster ice hockey coach development. In D.J. Pearsal \& A.B. Ashare (Eds.), Safety in ice hockey: Fourth volume, West Conshohocken: ASTM International.

Trudel, P., \& Gilbert, W. (2006). Coaching and coach education. In D. Kirk, M. O'Sullivan, \& D. McDonald (Eds.), Handbook of physical education (pp. 516-539). London: Sage.

Varga-Atkins, T., Qualter, A., \& O’Brien, M. (2009). School professionals' attitudes to continuing education in a networked context: Developing the model of 'believers, seekers, and sceptics.' Continuing education in Education, 35(3), 321-340.

Vickers, B. (2007). Newcomers and old-timers: Communities of Practice in coaching clinics. (Doctoral dissertation, University of Georgia). Retrieved from http://athenaeum.libs.uga.edu/handle/10724/10085?show=full 
Vygotsky, L. S. (1978). Mind in society: The development of higher psychological processes. Cambridge: Harvard University Press

Wenger, E. (2000). Communities of practice and social learning systems. Organization, 7(2), 225-246.

Werthner, P., \& Trudel, P. (2006). A new theoretical perspective for understanding how coaches learn to coach. The Sport Psychologist, 20, 198-212.

Woodman, L. (1989). The development of coach education in Australia. The Journal of the Australian Society for Sports History, 5(2), 204-224.

Wright, T., Trudel, P., \& Culver, D. (2007). Learning how to coach: The different learning situations reported by youth ice hockey coaches. Physical Education and Sport Pedagogy, 12(2), 127-144. 


\section{Table 1}

Criteria for web-based search for participants

1. University name

2. Name of head football strength and conditioning coach

3. Primary undergraduate degree

4. Primary graduate degree

5. Certification status with NSCA-CSCS

6. Certification status with CSCCa-SCCC

7. Other certifications

8. Years of full-time employment as collegiate strength and conditioning coach

9. Athletic website address 


\section{Table 2}

\section{Participant Involvement and Values In Continuing Education}

\begin{tabular}{|c|c|c|c|c|c|}
\hline Umbrella Group & FRQ & Higher Order Category & FRQ & Sub-Theme & FRQ \\
\hline \multirow{19}{*}{$\begin{array}{l}\text { Personal CE } \\
\text { Practice and } \\
\text { Engagement in } \\
\text { Learning }\end{array}$} & \multirow{19}{*}{8} & \multirow{4}{*}{ Learning through social connections } & \multirow{4}{*}{8} & Communicating with peers & 8 \\
\hline & & & & Learning from more capable others & 8 \\
\hline & & & & Visiting other strength and conditioning programs & 5 \\
\hline & & & & Learning from athletes & 1 \\
\hline & & \multirow{5}{*}{ Active involvement in self-study } & \multirow{5}{*}{8} & Research through exploring practices of opponents & 5 \\
\hline & & & & Reading to improve practice & 5 \\
\hline & & & & Learning through multimedia & 5 \\
\hline & & & & Writing for journals/books & 2 \\
\hline & & & & Use of NSCA online quizzes for continual learning & 1 \\
\hline & & \multirow{3}{*}{ Experience as vehicle of learning } & \multirow{3}{*}{7} & Learn from day-to-day experience & 8 \\
\hline & & & & Learn through personal internship experience & 2 \\
\hline & & & & Teach/Instruct classes & 1 \\
\hline & & \multirow{4}{*}{ Deliberate learning at conference } & \multirow{4}{*}{7} & Formal learning at conference presentations & 6 \\
\hline & & & & Conference networking & 3 \\
\hline & & & & Learning from vendors & 2 \\
\hline & & & & Active involvement in administering or operating conference & 1 \\
\hline & & \multirow{3}{*}{ Enrollment in formal graduate education } & \multirow{3}{*}{4} & Engagement in master's degree program & 4 \\
\hline & & & & Engagement in doctoral degree program & 1 \\
\hline & & & & No involvment in formal grad program, but active in coursework & 1 \\
\hline \multirow{21}{*}{$\begin{array}{l}\text { Values toward } \\
\text { coach learning and } \\
\text { active leadership } \\
\text { behavior with } \mathrm{CE}\end{array}$} & \multirow{21}{*}{8} & \multirow{6}{*}{$\begin{array}{l}\text { Responsibilities and skills of coaches for CE } \\
\text { learning }\end{array}$} & \multirow{6}{*}{8} & Responsibility for personal growth & 6 \\
\hline & & & & Actively seeking to improve personal practice & 5 \\
\hline & & & & Thinking like a teacher & 2 \\
\hline & & & & Understanding the importance of education & 2 \\
\hline & & & & Possessing a growth mindset & 2 \\
\hline & & & & Resting the ladder on the right wall and learning from legitimate sources & 2 \\
\hline & & \multirow{6}{*}{ Create nonformal CE situations for staff } & & Assist staff in learning & 5 \\
\hline & & & & Have organized learning curriculum for staff & 4 \\
\hline & & & 7 & Have professional CE requirements for staff & 4 \\
\hline & & & 1 & Have organized internship program/curriculum & 3 \\
\hline & & & & Mentor staff to hire later & 2 \\
\hline & & & & Minimal involvement in staff development & 1 \\
\hline & & & & Active as senior staff in organizations & 5 \\
\hline & & & & Maintain personal certification & 4 \\
\hline & & Active engagment in professional & 6 & Dual membership & 2 \\
\hline & & & & Contributed to journal or organizational periodical & 2 \\
\hline & & & & Assist with collaboration between organizations and NCAA & 2 \\
\hline & & & & Specific differences between organizations & 1 \\
\hline & & & & Both organizations provide educational resources & 1 \\
\hline & & Attitudes toward professional organizations & 4 & Certifications should not terminate learning & 1 \\
\hline & & & & Certification processes ever evolving since their inception & 1 \\
\hline & & Budget differences between schools & 6 & Different schools have different resources for staff & 6 \\
\hline Individual barriers & 6 & Unity within the Field: Bring professionals & 4 & Coaches should collaborate with colleagues during learning and practice & 4 \\
\hline & & Time Constraints & 2 & Limited time to learn due to demands of job & 2 \\
\hline $\begin{array}{l}\text { Organizational } \\
\text { barriers to CE }\end{array}$ & 3 & $\begin{array}{l}\text { Unity within the Field: Bring organizations } \\
\text { together }\end{array}$ & 3 & Organizations must create unified body of practice to enhance learning & 3 \\
\hline & & & & Understand evolution and future directions of the field & 7 \\
\hline & & Be more professional in learning and in & 8 & Assist in development of younger generations of coaches & 2 \\
\hline & & practice & 8 & Have skills to transition out of weight room late in career & 1 \\
\hline Suggestions for & & & & Be capable of handling administrative duties & 1 \\
\hline individual CE & 8 & & & Differentiate learning experiences throughout career & 4 \\
\hline enhancement & & Differentiate Learning Experiences & 6 & Do not rely soley on conference attendance for CE & 1 \\
\hline & & & & Organizations should offer and accept variety of CEU opportunities & 1 \\
\hline & & Identify and learn important skills and & 3 & Coaches must have general pedagogical skills & 3 \\
\hline & & knowledge & & Be aware of learning style and know your personal needs & 1 \\
\hline & & Lack of singular organization or & 3 & There exists minimal collaboration between organizations & 3 \\
\hline Suggestions for & & standardized education & & Holding a competitive edge limits sharing between coaches & 1 \\
\hline organzational CE & 4 & NCAA Rules May Inhibit Learning of & 3 & 5-Coach Rule limits FBS programs to only $5 \mathrm{~S} \& \mathrm{C}$ coaches & 3 \\
\hline & & Future Coaches & & Coaches must be certified to become full-time & 1 \\
\hline
\end{tabular}




\author{
Appendix A \\ Invitation to Participate Letter and Informed Consent
}

Coach:

You have been identified as a prospective participant in a research project involving the continuing education experiences of college football strength and conditioning coaches. This project is being conducted by Joshua G. Nelson, M.Ed., CSCS, USAW, a doctoral candidate in Kinesiology-PETE at West Virginia University. This project will be under the supervision of Kristen Dieffenbach, Ph.D., Athletic Coaching Education Assistant Professor at West Virginia University.

I would like to invite you to participate in this project which involves a brief online questionnaire (please follow link below) and a 45 minute telephone interview which will be audio recorded. Participation is completely voluntary and you will have the opportunity to skip any question during each the survey and interview. Further, you may terminate participation at any time. Following your interview, you will be able to review the transcription to ensure proper interpretation of your responses. All information from the project will remain as anonymous and confidential as possible. Every effort will be made to keep responses anonymous, however as the population of this study is small, it is possible that participants may be identified by responses given. Names will not be tied to the results in any way and at no point in the project will computer IP addresses be tracked. This project has been acknowledged and accepted by the Institutional Review Board at West Virginia University (Protocol \#1305043553).

Thank you for considering participation in this study. By agreeing to take part in this study you will be providing valuable information to further the understanding of how strength and conditioning professionals learn throughout their careers. If you have any questions regarding your participation in this study, please contact me by phone at (276) 233-5215 or by email at jnelso14@mix.wvu.edu or project supervisor Kristen Dieffenbach, Ph.D. by phone at (304) 2930847 or by email at kristen.diffenbach@ mail.wvu.edu. Thank you for your time and consideration in this project.

Sincerely,

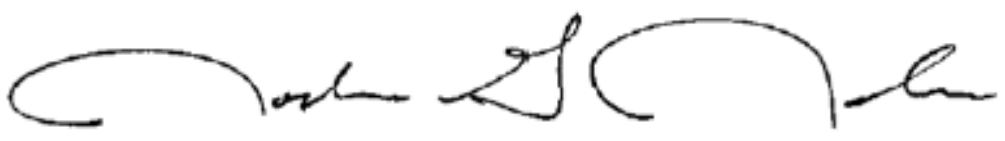

Joshua G. Nelson, M.Ed., CSCS, USAW 


\section{Appendix B}

Pre-Interview Online Questionnaire

Coach

Thank you for agreeing to participate in this research project involving the dispositions of NCAA-DI strength and conditioning coaches in regard to continuing education throughout their careers. Prior to the telephone interview, this questionnaire will be used to collect demographical information about your career and to confirm the actual date and time for the interview. According to my records, the scheduled time for the interview is at AM/PM Eastern Standard Time.

Again, thank you for participating in this research project. At any point during the process, you will have the right to skip any question and you may terminate your participation at any time. If you have any questions pertaining to your involvement in the project, feel free to contact the primary researcher Josh Nelson by phone at (276)233-5215 or by email at jnelso14@mix.wvu.edu or the project supervisor Kristen Dieffenbach, Ph.D. at (304)293-0847 or kristen.dieffenbach@mail.wvu.edu.

1. What is your gender?
a. Male
b. Female

2. What is your age?
a. $25-30$
b. $31-35$
c. $36-40$
d. $41-45$
e. $46-50$
f. 51-55
g. $56+$

3. What is your race?
a. Caucasian
b. African American
c. American Indian
d. Hispanic
e. Asian
f. Other

4. What degree levels do you currently hold? (choose all that apply)
a. B.A.
b. B.S.
c. M.S.
d. M.A. 

e. M.Ed.
f. Ed.D.
g. Ph.D.
h. Other

5. What was your primary undergraduate degree field of study?
a. Health and/or Physical Education
b. Kinesiology
c. Exercise Science
d. Exercise Physiology
e. Health \& Wellness
f. Other

6. What was your primary graduate degree field of study?
a. Health and/or Physical Education
b. Kinesiology
c. Exercise Science
d. Exercise Physiology
e. Health \& Wellness
f. N/A
g. Other

7. How many years have you been in a post graduate assistant full-time collegiate strength and conditioning position?
a. $10-14$
b. $15-19$
c. 20-25
d. 26

8. What is your current position job title?
a. Assistant Athletic Director for Sport Performance
b. Director of Strength and Conditioning
c. Head Strength and Conditioning Coach
d. Coordinator of Strength and Conditioning
e. Other

9. Which of the following best describes your progression of your career as a strength and conditioning coach?
a. Intern $\rightarrow$ Graduate Assistant $\rightarrow$ Assistant $\rightarrow$ Associate $\rightarrow$ Head
b. Graduate Assistant $\rightarrow$ Assistant $\rightarrow$ Associate $\rightarrow$ Head
c. Assistant $\rightarrow$ Associate $\rightarrow$ Head
d. Assistant $\rightarrow$ Head
e. Other

10. Who do you report to as a superior in your current position?

a. Athletic Director 

b. Assistant Athletic Director
c. Head Football Coach
d. Other

11. How many years have you been in your current position at your institution?
a. $0-2$
b. $3-5$
c. $6-8$
d. $9-10$
e. $10+$

12. What professional associations are you a member of? (Choose all that apply)
a. National Strength and Conditioning Association (NSCA)
b. Collegiate Strength and Conditioning Coaches Association (CSCCa)
c. United States of America Weightlifting (USAW)
d. American College of Sports Medicine (ACSM)
e. Other

13. What professional credentials do you hold?
a. NSCA - Certified Strength and Conditioning Specialist (CSCS)
b. CSCCa - Strength and Conditioning Coach Certified (SCCC)
c. USAW - Sport Performance Coach
d. ACSM - PT - American College of Sports Medicine
e. NSCA - Certified Personal Trainer (CPT)
f. Other

14. What percentage of time do you spend with the following sports?
a. Baseball, Men's
b. Basketball, Men's
c. Basketball, Women's
d. Bowling, Women's
e. Cross Country, Men's
f. Cross Country, Women's
g. Equestrian, Women's
h. Fencing, Men's
i. Fencing, Women's
j. Field Hockey, Women's
k. Football, Men's
1. Golf, Men's
m. Golf, Women's
n. Gymnastics, Men's
o. Gymnastics, Women's
p. Ice Hockey, Men's
q. Ice Hockey, Women's
r. Rifle, Men's
s. Rifle, Women's 
t. Rowing, Women's

u. Rugby, Women's

v. Sand Volleyball, Women's

w. Skiing, Men's

x. Skiing, Women's

y. Soccer, Men's

z. Soccer, Women's

aa. Softball, Women's

bb. Swimming \& Diving, Men's

cc. Swimming \& Diving, Women's

dd. Tennis, Men's

ee. Tennis, Women's

ff. Track \& Field (Indoor/Outdoor), Men's

gg. Track \& Field (Indoor/Outdoor), Women's

hh. Volleyball, Men's

ii. Volleyball, Women's

jj. Water Polo, Men's

kk. Water Polo, Women's

11. Wrestling, Men's

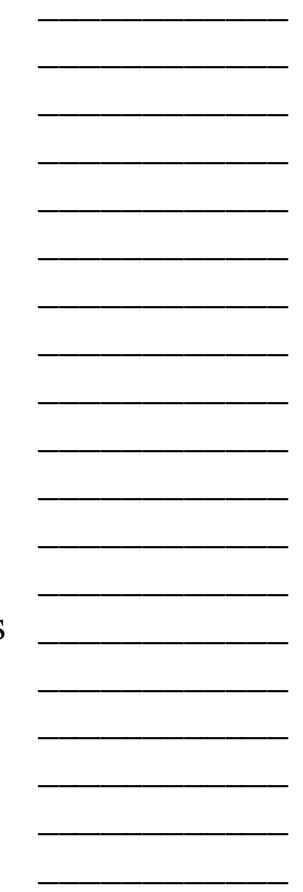




\section{Appendix C \\ Semi-Structured Interview Guide and Script}

Hello, my name is Josh Nelson and I'm calling from West Virginia University and the Athletic Coaching Education Department. Previously, you indicated that you were interested in participating in a project dealing with the dispositions of strength and conditioning coaches toward continuing education throughout their career.

Is this a convenient time to continue? Is it ok if I begin the recording our conversation for the purpose of obtaining all information from the interview? The recording will later be transcribed verbatim and will be used for data analysis. Responses will be anonymous and all personal information will be removed and protected from this project. Following completion of transcription, you will receive a copy of the transcription to ensure that proper meaning was delivered during the interview.

$$
\begin{aligned}
& \text { Option A - No } \\
& \text { Option B - Yes }
\end{aligned}
$$$$
\text { go to better time section }
$$$$
\text { go to continue with interview section }
$$

\section{Option A: Better time}

This interview should take roughly 30-45 minutes and can be arranged to fit your schedule. Is there a good time in the near future that would fit your schedule?

\section{--- Begin Recording ---}

\section{Option B: Continue with interview}

Coach , for research purposes, I will need to repeat the previous comments in order to ensure they are added to our transcription.

Coach thank you for agreeing to participate in this study. My name is Josh Nelson and I'm calling from West Virginia University and the Athletic Coaching Education Department. This research project pertains to the dispositions of NCAA-DI strength and conditioning coaches in regard to continuing education experiences. Participation in this study is completely voluntary and you have the right to skip any question you wish and may terminate participation in this study at any time. All information from the interview will be completely confidential. This interview will take roughly 45 minutes and has been approved by the Institutional Review Board (IRB) at West Virginia University. Do you have any questions before we begin?

Are you ready to continue?

$$
\text { Option A - Yes }
$$




$$
\begin{array}{ll}
\text { Option B }- \text { No } & \text { go to better time section } \\
\text { Option } \mathrm{C}-\text { Wants more info } & \text { move to details section }
\end{array}
$$

\section{Details}

The purpose of this study is to evaluate the dispositions of NCAA-DI strength and conditioning coaches in regard to continuing education throughout their careers. Data collected via interview will be used in a qualitative analysis to produce a better picture of what college strength and conditioning coaches think about their involvement with continuing education. Individual participants will not be identified at any time during this study.

Are you ready to continue?

$$
\begin{aligned}
& \text { Option A - Yes } \\
& \text { Option B - No }
\end{aligned}
$$$$
\text { go to begin interview section }
$$

go to better time section

\section{Begin interview}

Semi-structured Interview Guide Questions

\section{Introduction}

1. Please me a little bit about yourself and your path to become a head football strength and conditioning coach.

$$
\text { Probes: }
$$

a. What made you get involved initially?

b. What made that experience so influential?

c. What experiences did you have before entry into the profession that put you in position for this profession?

d. Can you tell me about your career progression as a collegiate strength and conditioning coach?

2. Can you share any experiences that you have had as a collegiate strength and conditioning coach that has been influential on your development?

\section{Probes:}

a. Why was that so influential?

b. Where there additional factors that you felt as though helped you continue to improve?

\section{Involvement in Continuing education}

1. Please describe any responsibilities or duties that you have currently or have had in the past with your professional organizations beyond being a member and/or maintaining certification.

\section{Probes:}


a. How long have you been involved with that position?

b. How did you get involved with that initially?

c. Can you give a more detailed description of your responsibilities with that position?

2. What continuing education experiences do you regularly engage in?

Probes:

a. Can you give a more detailed description of those experiences?

b. Why do you engage in those experiences over other forms of continuing education?

c. What influences your engagements in $\mathrm{CE}$ or what makes these experiences so attractive to you?

d. Are there characteristics or components that you prefer above others?

e. Are there any forms of continuing education that you don't engage in or aren't interested in and why?

3. Please describe any experiences that you have had when involved in these forms of continuing education that makes you gravitate toward being involved in such experiences.

Probes:

a. Could you say something more about your experience with that and how it drives you to want to be involved with that form of continuing education?

b. What do you think separates the previously mentioned experiences from other learning opportunities that may not have been as effective?

4. Are there any learning activities or forms of continuing education that you have engaged in during the past that you don't currently?

Probes:

a. If yes - Why did you begin to stop using this form of continuing education?

b. If no - How has being consistent in your continuing education pursuits helped you?

5. What are your thoughts on the continuing education opportunities that are offered by the different professional associations for collegiate strength and conditioning coaches?

Probes:

a. How does required continuing education influence your involvement in such learning experiences?

b. Can you expand on any positive/negative experiences that you have had with required continuing education?

\section{Values toward Continuing education}

1. What's your philosophy toward career-long learning of collegiate strength and conditioning coaches?

Probes:

a. Could you expand on how your values toward continuing education have changed throughout your career? 
b. Can you elaborate on any examples of specific events that may have sparked this change?

2. Can you describe any continuing education programs that you have developed for yourself or for your staff?

Probes:

a. What went into the development of such a program?

b. Can you give a more detailed description of the formats of continuing education that are used in this program?

c. Could you say something more about the content that is covered in this continuing education program?

Progression and Improvement of Continuing education for Strength and Conditioning

1. How could continuing education that is offered currently for collegiate strength and conditioning coaches be changed to benefit you more?

Probes:

a. What types of experiences would you like to see offered more or less?

b. Can you give a more detailed description of how or if the NSCA and CSCCa should be involved in helping to improve continuing education in the field?

Open thoughts

1. I am finished with my questions, but I want to leave some time if you have anything that you would like to add to be captured in the data?

Probes:

a. Other experiences regarding your development as a coach.

b. Stories or past experiences in regard to learning through your career.

c. Motivators to continue to develop?

d. Inhibitors preventing you from continuing to develop? 